\title{
FINITE ELEMENT ANALYSIS OF SELF-PIERCE \\ RIVETING IN MAGNESIUM
}

ALLOYS SHEETS

\author{
by \\ JOAO FELIPE CARVALHO DE MORAES \\ J. BRIAN JORDON, COMMITTEE CHAIR \\ MARK E. BARKEY \\ YUEBIN GUO
}

\begin{abstract}
A THESIS
Submitted in partial fulfillment of the requirements for the degree of Master of Science in the Department of Mechanical Engineering in the Graduate School of The University of Alabama
\end{abstract}

TUSCALOOSA, ALABAMA 
Copyright Joao Felipe Carvalho de Moraes 2014 ALL RIGHTS RESERVED 


\begin{abstract}
Conventional fusion joining methods such as resistance spot welding have been demonstrated to not be effective for magnesium alloys. Therefore, self-pierce riveting (SPR) has been presented as an attractive joining technique for these lightweight metals. However, SPR must be performed at elevated temperatures because of the low ductility of magnesium alloys at room temperature. Even though the SPR joining process has been established on magnesium alloys, this joining process is not optimized. As such, this study establishes the first attempt at simulating the SPR of magnesium alloys through the use of the finite element method. An internal state variable (ISV) plasticity and damage material model was employed with results in good agreement to experimental data. The results of this study show that the ISV material model is ideally suited for modeling the SPR process in magnesium alloys.
\end{abstract}




\section{DEDICATION}

This thesis is dedicated to everyone who helped me during this period. In particular, my family and close friends, who always cheered and supported me. 


\section{LIST OF ABBREVIATIONS AND SYMBOLS}

$S P R \quad$ Self-pierce riveting

$I S V \quad$ Internal state variable

$R S W \quad$ Resistance spot welding

$D R X$ Dynamic recrystallization

FEA Finite element analysis

$B C J$ Model created by Bammann, Chiesa and Johnson

$F \quad$ Deformation gradient

$F_{e} \quad$ Deformation gradient, elastic component

$F_{p} \quad$ Deformation gradient, plastic component

$F_{d} \quad$ Deformation gradient, damage component

$F_{t h} \quad$ Deformation gradient, thermal component

$L_{e} \quad$ Elastic velocity gradient

$L_{d} \quad$ Velocity gradient associated with damage

$L_{p} \quad$ Plastic velocity gradient

$L_{t h} \quad$ Velocity gradient, thermal component

$D_{e} \quad$ Symmetric part of the elastic velocity gradient

$D_{p} \quad$ Symmetric part of the plastic velocity gradient

$D_{d} \quad$ Symmetric part of the velocity gradient associated with damage

$D_{t h} \quad$ Symmetric part of the velocity gradient, thermal component (thermal stretching) 
$\phi \quad$ Damage or porosity

$W_{e} \quad$ Skew symmetric part of the elastic velocity gradient

$W_{p} \quad$ Skew symmetric part of the plastic velocity gradient

$W_{d} \quad$ Skew symmetric part of the velocity gradient associated with damage

$W_{t h} \quad$ Skew symmetric part of the velocity gradient, thermal component

SSD Statiscally stored dislocations

$\alpha \quad$ Kinematic hardening internal state variable

$\kappa \quad$ Isotropic hardening internal state variable

T Temperature

$\lambda \quad$ Lamè constant

$\mu \quad$ Shear modulus

$\stackrel{\circ}{\sigma} \quad$ Convected Cauchy stress

A Expansion coefficient

GND Geometrically necessary dislocations

$C_{v} \quad$ Heat capacity

$\rho \quad$ Density of the material

$Y(T) \quad$ Determines the rate-independent limit of yield stress

$f(T) \quad$ Determines the strain rate at which the yield behavior exhibits a transition from being essentially rate-independent to being rate-dependent

$V(T)$ Determines the magnitude of the rate-dependence

$r_{s}(T) \quad$ Kinematic static recovery parameter

$R_{s}(T) \quad$ Isotropic static recovery parameter

$r_{d}(T)$ Kinematic dynamic recovery parameter

$R_{d}(T)$ Isotropic dynamic recovery parameter 
$h(T) \quad$ Kinematic hardening parameter

$H(T) \quad$ Isotropic hardening parameter

$C_{l} \quad$ Constant term in $\mathrm{V}(\mathrm{T})$ Arrhenius-type equation which determines the magnitude of rate dependence on yielding (units $=\mathrm{MPa}$ )

$C_{2}$ Temperature dependent activation term in $\mathrm{V}(\mathrm{T})$ Arrhenius-type equation (units=Kelvin)

$C_{3} \quad$ Constant term in $\mathrm{Y}(\mathrm{T})$ Arrhenius-type equation which is the rate independent yield stress (units $=\mathrm{MPa}$ )

$C_{4} \quad$ Temperature dependent activation term in $\mathrm{Y}(\mathrm{T})$ Arrhenius-type equation (units=Kelvin)

$C_{5} \quad$ Constant term in $\mathrm{f}(\mathrm{T})$ Arrhenius-type equation which determines the transition strain rate from rate independent to dependent yield (units $=1 / \mathrm{sec}$ )

$C_{6} \quad$ Temperature dependent activation term in $\mathrm{f}(\mathrm{T})$ Arrhenius-type equation (units=Kelvin)

$C_{7} \quad$ Constant term in $r_{d}(T)$ equation which describes the kinematic dynamic recovery (units=1/MPa)

$C_{8} \quad$ Temperature dependent activation term in $r_{d}(T)$ equation (units=Kelvin)

$C_{9} \quad$ Constant term in $h(T)$ equation which describes the kinematic anisotropic hardening modulus (units $=\mathrm{MPa}$ )

$C_{10}$ Temperature dependent activation term in $h(T)$ equation (units=Kelvin)

$C_{11} \quad$ Constant term in $r_{s}(T)$ equation which describes the kinematic static recovery (units $=1 /(\mathrm{MPa} \mathrm{sec})$ )

$C_{12}$ Temperature dependent activation term in $r_{s}(T)$ equation (units=Kelvin)

$C_{13} \quad$ Constant term in $R_{d}(T)$ equation which describes the isotropic dynamic recovery (units $=1 / \mathrm{MPa}$ )

$C_{14} \quad$ Temperature dependent activation term in $R_{d}(T)$ equation (units=Kelvin)

$C_{15}$ Constant term in $H(T)$ equation which describes the isotropic hardening modulus (units $=\mathrm{MPa}$ )

$C_{16}$ Temperature dependent activation term in $H(T)$ equation (units=Kelvin)

$C_{17} \quad$ Constant term in $R_{s}(T)$ equation which describes the isotropic static recovery (units=1/(MPa sec)) 
$C_{18} \quad$ Temperature dependent activation term in $R_{S}(T)$ equation (units=Kelvin)

CF Coefficient of friction 


\section{ACKNOWLEDGMENTS}

I would like to thank the many colleagues, friends, and faculty members who have helped me with this research project. I am very grateful to Dr. James Brian Jordon, my advisor and chairman of this thesis, for sharing his research expertise and motivating me. I would also like to thank all of my committee members, Dr. Yuebin Guo for his support, and Dr. Mark E. Barkey for his valuable contribution regarding the finite element analysis (FEA). I am very thankful to Dr. Wang at GM for sharing experimental data, and to Dr. Douglas J. Bammann for his priceless contribution concerning the FEA and the material model used. Lastly, I am indebted to Department of Mechanical Engineering at The University of Alabama for the support of this project.

This research would not have been possible without the help of my friends and fellow graduate students, specially: Mariangela Vecchiarini, Rogie Irwin Rodriguez, Robert Mcullough and Harish Rao, and of course of my family who never stopped supporting my decisions. 
CONTENTS

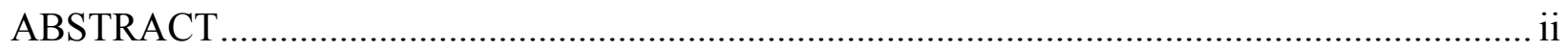

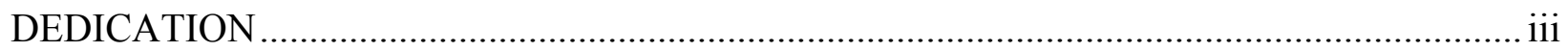

LIST OF ABBREVIATIONS AND SYMBOLS ……........................................................ iv

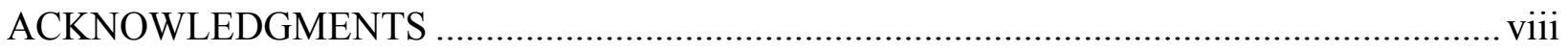

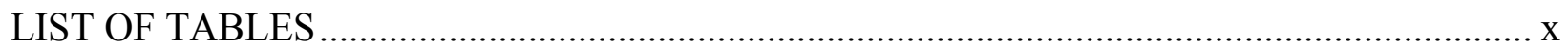

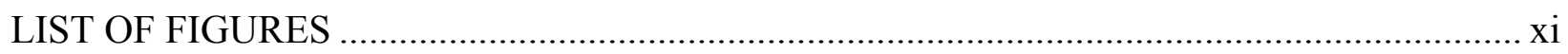

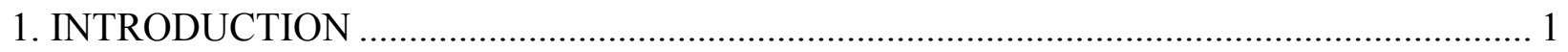

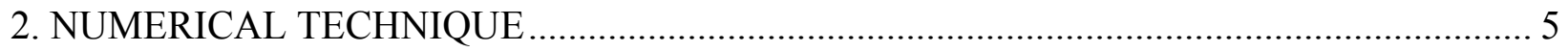

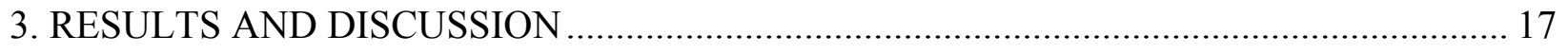

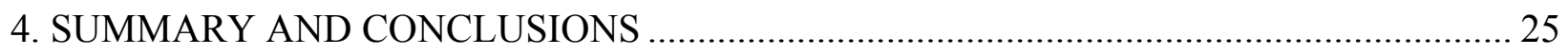

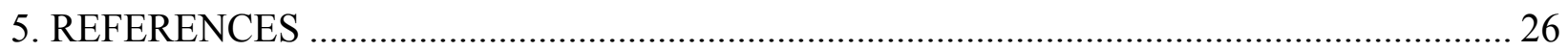

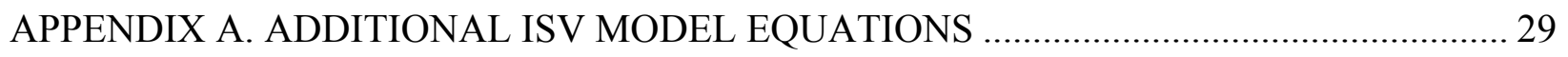

APPENDIX B. SAMPLE KEYWORD USED FOR SELF-PIERCE RIVETING PROCESS IN

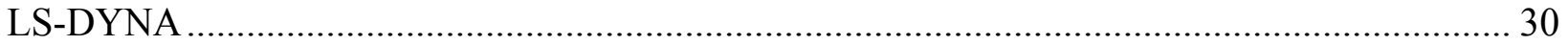

APPENDIX C. SAMPLE KEYWORD USED FOR SPRINGBACK PROCESS IN LS-DYNA 38 APPENDIX D. SAMPLE KEYWORD USED FOR COOLING PROCESS IN LS-DYNA ...... 44 


\section{LIST OF TABLES}

Table 1. Dimensions of the self-pierce riveting die and rivet............................................... 13

Table 2. Coefficients of friction (CF) values used for the simulations in this study ................. 16 


\section{LIST OF FIGURES}

Figure 1. Schematic of the self-pierce riveting process steps ........................................... 2

Figure 2. Comparison between the experimental and the BCJ model correlation results of a

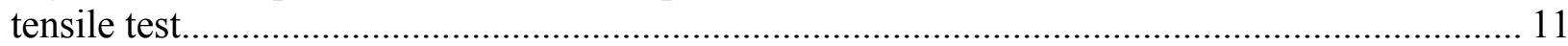

Figure 3. Self-pierce riveting die and rivet geometry ........................................................ 13

Figure 4. Initial configuration of the axisymmetric self-pierce riveting finite element model..... 14

Figure 5. The self-pierce riveting process at different time steps ..................................... 18

Figure 6. Comparison between numerical analysis and experimental results for of the final shape

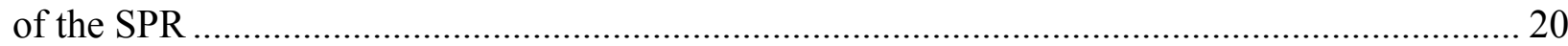

Figure 7 . History plot of one element from top sheet ................................................... 22

Figure 8. Comparison between numerical analysis and experimental results showing crack prediction at room temperature for SPR of $\mathrm{Mg}$ alloy. ........................................................... 23 


\section{INTRODUCTION}

The need to decrease fuel consumption and greenhouse gas emissions have led the automotive industry to seek materials with enhanced strength-to-weight ratios [1]. Suitable materials such as aluminum and magnesium alloys are being employed in body-in-white construction. In fact, in certain cases, the use of lightweight metals like magnesium alloys can save significant weight while maintaining acceptable structural performance. Nonetheless, traditional joining techniques like resistance spot welding (RSW), traditionally applied to join steel metal, present enormous difficulties in joining magnesium alloys $[2,3]$. These difficulties are mostly due to the high electrical conductivity and low heat generation of magnesium alloys which in turn requires high welding currents [4] leading to poor welding characteristics. While many joining technologies exist, self-piercing riveting (SPR) is an appealing joining processes for magnesium alloys sheets [5].

The SPR process can be illustrated in four steps, as shown in Fig. 1: (1) the blank holder presses the two sheets against the die; (2) the punch drives a semi-tubular rivet into the upper sheet; (3) the material of the bottom plate flows into the die and the rivet shank begins to flare outward, forming a mechanical inter-lock between the two sheets; (4) and lastly, the punch is released [6]. 


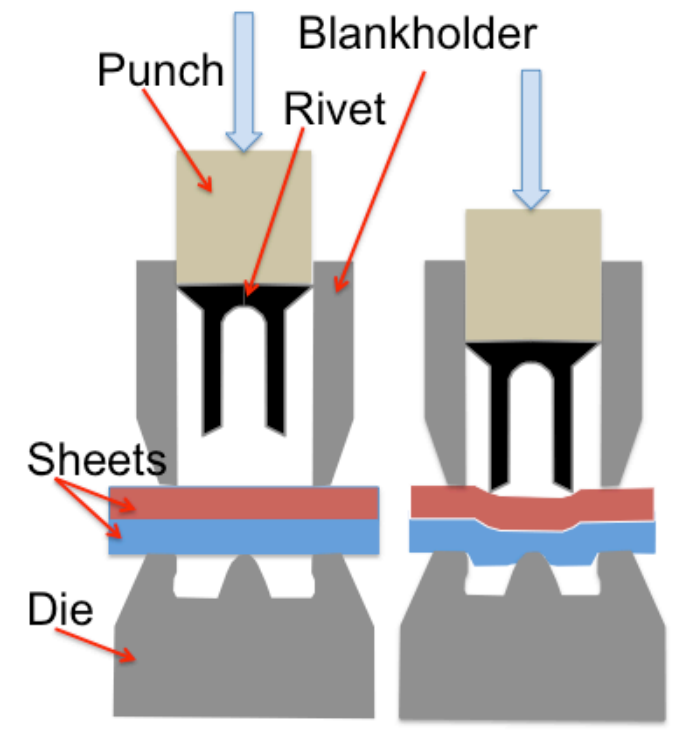

1)
2)

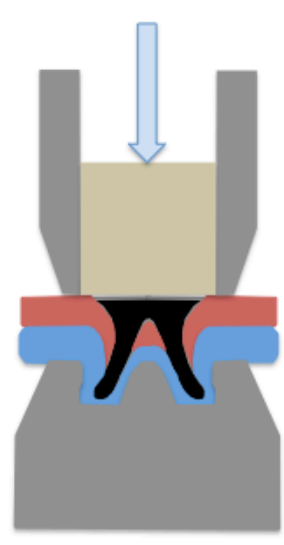

3)

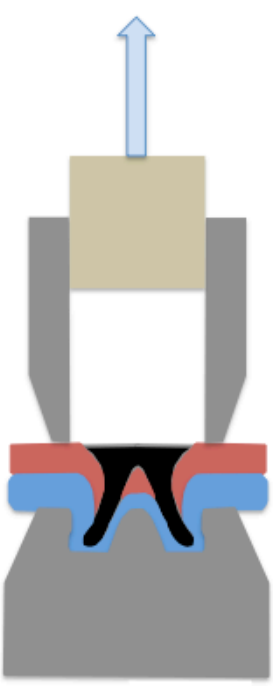

4)

Figure 1. Schematic of the self-pierce riveting process steps: 1) clamping, 2) piercing, 3) Mechanical interlock obtained, 4) punch release

It has been demonstrated that the SPR process produces joints of comparable static strength and superior fatigue performance to RSW and also produces promising results in peel and shear testing [7]. Although the SPR has many benefits, it does present some disadvantages including the following: both sides of the sheet must be accessible to apply the SPR technique; it is unsuitable for brittle substrates; prominences and indents related to the forming process may not be aesthetically acceptable; and relatively high forces are required for the forming process. As such, it is the difficulty of applying the SPR process to brittle materials that represents an obstacle in joining magnesium alloy sheets. In fact, employing the SPR process on AZ31 magnesium alloy at low or intermediate temperatures (i.e lower than $150^{\circ} \mathrm{C}$ ) results in cracks in the deformed material that typically originate in the shear zones where the strain localization arises due to limited dynamic recrystallization (DRX). The high rate of deformation in SPR does not permit sufficient time for DRX to occur during the deformation. Since DRX is improved at elevated temperatures, cracking of the joint can be prevented by preheating the AZ31 magnesium 
alloy prior to SPR. In fact, experiments have shown that riveting AZ31 magnesium alloy at elevated temperatures largely removed the defects from the joint at temperatures of $200^{\circ} \mathrm{C}$ or higher $[5,8]$. In addition, it has been demonstrated that the joint strength increased when the preheat temperature was raised from ambient to $200^{\circ} \mathrm{C}$. This increase in strength is due to the reduction in joint discrepancies and an increase in mechanical interlock between the rivet and the work pieces [5].

In regards to modeling the SPR process, several numerical studies on aluminum alloys have been conducted. One of the first to model the SPR process, Porcaro et al. [6] demonstrated good comparison between experimental results and finite element analysis (FEA) by using LSDYNA 2D axisymmetric model while employing r-adaptivity re-meshing techniques and a geometrical failure criterion based on the change in sheet thickness. Casalino et al. [9] also showed good agreement between experimental and finite element results, but used a failure criterion based on effective plastic strain rather then a sheet thinning technique. Several other numerical studies of the SPR process have been conducted with similar results [10,11]. Regarding the springback analysis, the common approach is to perform the piercing step in explicit and perform the springback using implicit [6,9-11].

While recent FEA of SPR on aluminum alloy sheets has demonstrated the effectiveness of these modeling techniques, to the best of the authors' knowledge, there is no study published work regarding FEA of SPR in magnesium alloys. More importantly, previous studies [6,9-11] have not considered strain rate, temperature, stress-state dependencies, or heat generation due to plastic deformation, as these effects are not easily captured by simple piece-wise linear material models. As such, the purpose of this paper is to, for the first time, use a large scale plasticity and 
damage model based on internal state variables (ISV) to capture the complex physics occurring during the SPR process and compare to experimental results. 


\section{NUMERICAL TECHNIQUE}

The material model employed in this study is the internal state variable (ISV) plasticity and damage based upon ductile void growth by Bammann [12], Bammann \& Aifantis [13] and Bammann et al. [14] (also called the BCJ model).. This model was later modified to capture damage arising from void nucleation, and coalescence, in addition to the void growth. [14-15], and later modified to incorporate more accurate physics [16]. It has been used to predict the behavior of metals under different loading conditions [17] on many different industrial and manufacturing applications (including forging, metal cutting, heat treatment, resistance welding) [18]. The BCJ model is a physically based plasticity and damage constitutive model that involves microstructural content and is consistent with continuum level kinematics, kinetics, and thermodynamics [19]. This model was originally developed for problems with strain rates smaller than the shock regime, involving large strains and or damage. Generally, whenever either or both of these mechanisms are present, localizations occur, driven by gradients in strain/damage and inherently coupled to the softening resulting from the self-heating. For this reason, the BCJ model can be applied to simulate a self-pierce riveting process even at high temperatures and strain rates due to the kinematic and isotropic hardening and recovery components.

The kinematics of the BCJ model are based upon the multiplicative decomposition of the deformation gradient into elastic, damage and plastic parts.

$$
\mathbf{F}=\mathbf{F}_{e} \mathbf{F}_{t h} \mathbf{F}_{d} \mathbf{F}_{p}
$$


As a result, other kinematic quantities naturally follow and are defined with respect to any of the possible configurations via standard push - forward, pull - back of any of the configurations operations. For example, the velocity gradient naturally decomposes in the current configuration into the following additive parts.

$$
\mathbf{L}=\dot{\mathbf{F}} \mathbf{F}^{-1}=\dot{\mathbf{F}}_{e} \mathbf{F}_{e}^{-1}+\mathbf{F}_{e} \dot{\mathbf{F}}_{t h} \mathbf{F}_{t h}^{-1} \mathbf{F}_{e}^{-1}+\mathbf{F}_{e} \mathbf{F}_{t h} \dot{\mathbf{F}}_{d} \mathbf{F}_{d}^{-1} \mathbf{F}_{t h}^{-1} \mathbf{F}_{e}^{-1}+\mathbf{F}_{e} \mathbf{F}_{t h} \mathbf{F}_{d} \dot{\mathbf{F}}_{p} \mathbf{F}_{p}^{-1} \mathbf{F}_{d}^{-1} \mathbf{F}_{t h}^{-1} \mathbf{F}_{e}^{-1}
$$

Where, $\boldsymbol{L}_{e}=\dot{\boldsymbol{F}}_{e} \boldsymbol{F}_{e}^{-1}$ is the elastic the velocity gradient defined with respect to the current configuration, $\tilde{\mathbf{L}}_{d}=\dot{\mathbf{F}}_{d} \mathbf{F}_{d}^{-1}$ is the velocity gradient associated with damage and is defined with respect to the configuration $\boldsymbol{F}_{d}$, while $\overline{\mathbf{L}}_{p}=\dot{\mathbf{F}}_{p} \mathbf{F}_{p}^{-1}$ is the plastic velocity gradient residing in the configuration defined with respect to $\boldsymbol{F}_{p}$. The velocity gradient can obviously be pulled back to any of the configurations, as can any of the finite deformation strain measures. However, it is noteworthy that the total strain or velocity gradient is simply the sum of the elastic damage and plastic parts, each defined by the appropriate pull - back operation. The BC J model is defined with respect to the configuration that is described by $\boldsymbol{F}_{p}$, the configuration reached by unloading through the elastic and damage configurations. The Helmholtz free energy was written as a function of the elastic strain and the ISV all described with respect to this configuration. The assumption that the free energy is a quadratic function of the elastic strain, results in a Hooke's law the expression, which after taking the material derivative and pushing forward to the current configuration yields an expression (in rate form) for linear elasticity in the current configuration.

$$
\stackrel{\circ}{\sigma}=\lambda(1-\phi) \operatorname{Tr} \mathbf{D}_{e}+2 \mu(1-\phi) \mathbf{D}_{e}
$$

where $\boldsymbol{D}_{e}$ is the symmetric par of the elastic velocity gradient and $\phi$ is the porosity or damage. 
Recall, in each velocity gradient $L$ may be decomposed into a symmetric part, $\boldsymbol{D}$ and a skew symmetric part $\boldsymbol{W}$.

$$
\begin{gathered}
\mathbf{L}=\mathbf{D}+\mathbf{W} \\
\mathbf{L}_{e}=\mathbf{D}_{e}+\mathbf{W}_{e} \\
\mathbf{L}_{p}=\mathbf{D}_{p}+\mathbf{W}_{p} \\
\mathbf{L}_{d}=\mathbf{D}_{d}+\mathbf{W}_{d} \\
\mathbf{L}_{t h}=\mathbf{D}_{t h}+\mathbf{W}_{t h}
\end{gathered}
$$

Since the damage and thermal parts of the deformation gradient are assumed to be isotropic, there is no skew symmetric part for either. So,

$$
\begin{gathered}
\mathbf{D}=\mathbf{D}_{e}+\mathbf{D}_{p}+\mathbf{D}_{d}+\mathbf{D}_{t h} \\
\mathbf{W}=\mathbf{W}_{e}+\mathbf{W}_{p}
\end{gathered}
$$

but since the plastic part is neglected in the BCJ model,

$$
\boldsymbol{W}_{p}=0 \Rightarrow \boldsymbol{W}_{e}=\boldsymbol{W}
$$

therefore, to complete the model, constitutive equations are necessary for $\boldsymbol{D}_{p}, \boldsymbol{D}_{d}$ and $\boldsymbol{D}_{t h}$. These flow rules are given in Eq. 12, where $\sigma^{\prime}$ is the deviatoric Cauchy stress and $\alpha^{\prime}$ is the tensor variable. $\boldsymbol{D}^{\text {th }}$ is the thermal stretching (Eq. 13) assuming isotropic thermal expansion where $A$ is the expansion coefficient, $\mathbf{1}$ is an unit tensor and $T$ is the temperature, and assuming an isotropic volumetric rate of change due to void growth in terms of the porosity or damage $\phi$ in equation (14). 


$$
\begin{gathered}
\mathbf{D}^{p}=f(T) \sinh \left[\frac{\left\|\boldsymbol{\sigma}^{\prime}-\boldsymbol{\alpha}\right\|-\boldsymbol{\kappa}-Y(T)}{V(T)}\right] \frac{\boldsymbol{\sigma}^{\prime}-\boldsymbol{\alpha}}{\left\|\boldsymbol{\sigma}^{\prime}-\boldsymbol{\alpha}\right\|} \\
\mathbf{D}^{t h}=A T \mathbf{1} \\
\mathbf{D}_{d}=\frac{\dot{\phi}}{3(1-\phi)} \mathbf{1}
\end{gathered}
$$

The kinematic hardening internal state variable $(\alpha)$ and the isotropic hardening internal state variable $(\kappa)$ are given in Eqs. 15 and 16, respectively. The evolution of the internal state variables $\alpha$ and $\kappa$ is defined in a hardening minus recovery format. The isotropic hardening variable $\kappa$, is motivated by densities of statistically stored dislocations (SSD) and are generally created and stored within grains. The kinematic hardening variable $\alpha$, is motivated by geometrically necessary dislocations (GND) or compatibility dislocations that are created to restore compatibility at boundaries between parts of the crystal oriented differently with respect to each other, such as grain boundaries. Dislocations of the same sign piled up against a boundary are also represented as GNDs and their motion under load reversal gives rise to an apparent softening or a Bauschinger effect.

$$
\begin{gathered}
\stackrel{o}{\boldsymbol{\alpha}}=h(T) \mathbf{D}^{p}-\left[r_{d}(T)\left\|\mathbf{D}^{p}\right\|+r_{s}(T)\right] \mid \boldsymbol{\alpha} \| \boldsymbol{\alpha} \\
\dot{\boldsymbol{\kappa}}=H(T) \mathbf{D}^{p}-\left[R_{d}(T)\left\|\mathbf{D}^{p}\right\|+R_{s}(T)\right] \boldsymbol{\kappa}^{2}
\end{gathered}
$$

Temperature change due to deformation is taken into account in Eq. 17, where $\rho$ is the density of the material, and $\mathrm{C}_{\mathrm{v}}$ is the heat capacity. In this equation adiabatic temperature change is assumed, where $90 \%$ of the plastic work is dissipated as heat. The evolution of the damage (void growth) parameter $\phi$, is expressed in Eq. 18 and 19. 


$$
\begin{gathered}
T=\frac{0.9}{\rho C_{v}}\left(\boldsymbol{\sigma} \cdot \mathbf{D}^{p}\right) \\
\dot{\phi}=\beta\left[\frac{1}{(1-\phi)^{N}}-(1-\phi)\right]^{\left|\mathbf{D}^{p}\right|} \\
\beta=\sinh \left[\frac{2(2 N-1) p}{(2 N-1) \bar{\sigma}}\right]
\end{gathered}
$$

Equations (18) and (19), describing ductile void growth were developed by Cocks and Ashby [20,21]. Notice the strong dependence on the stress triaxiality. At high pressures equation (19) and equation (14) and the spherical part of Hooke's law (pressure, where the bulk modulus is degraded by the damage) describe a competitive process. As increased pressure drives the growth of porosity, the increased porosity slows the evolution of the pressure. This leads to a natural saturation of the porosity. Equation (14) is often neglected at low to moderate pressures, as the degradation of the elastic moduli by the damage is sufficient to predict the evolution of the porosity. Also, equation (14) causes a strong numerical stiffness in the solution of the system of ordinary differential equations and results in more enhanced solution techniques and greatly increases the computational time.

The model parameters $V ; Y ; H ; R_{d} ; R_{s} ; h ; r_{d} ; r_{s}$, are functions of temperature $(T)$, stress state and strain rate and are correlated to experiments. The rate-independent limit of yield stress is set by $Y(T)$. The $f(T)$ term determines the strain rate at which the yield behavior exhibits a transition from being essentially rate-independent to being rate-dependent and the $V(T)$ term determines the magnitude of the rate-dependence. The $H(T)$ and $h(T)$ terms are the hardening moduli, $r_{s}(T)$ and $R_{S}(T)$ are scalar functions describing the diffusion controlled 'static' or 'thermal' recovery, and $r_{d}(T)$ and $R_{d}(T)$ are the functions describing dynamic recovery. The 
deviatoric inelastic flow rule, Eq. 15, captures the effect of creep and plasticity in terms of kinematic and isotropic hardening, temperature, and strain rate.

In this study, the numerical results are compared to SPR produced by Wang et al. [5]. In this study, $200^{\circ} \mathrm{C}$ and $110 \mathrm{~mm} / \mathrm{sec}$ were experimentally found to be the optimal temperature and riveting velocity, respectively, for producing defect free joints. As such, these parameters were chosen as a baseline for SPR simulations. The model constants $\mathrm{C}_{1}$ to $\mathrm{C}_{18}$ (refer to Appendix A for equation $\mathrm{C}_{1}-\mathrm{C}_{18}$ ) were calibrated for the stress-strain curves for $\mathrm{AZ31}$ at various stain-rates. The calibrated model was verified by comparing experimental literature data with simulations of a tensile test of a single element in LS-Dyna with dimensions $1 \times 1 \times 1 \mathrm{~mm}$, and a $0.1 \times 0.1 \mathrm{~mm}$ element 2D axisymmetric shell for high strain rates applied in the explicit method. Figure 2 shows the comparison of the ISV plasticity model to experimental tensile stress-strain results for room temperature quasi-static [22] quasi-static at $370^{\circ} \mathrm{C}$ [23], and $300^{\circ} \mathrm{C}$ at strain rate of $1000 / \mathrm{s}$ [22]. All stress-strain data used here was obtained from axial loading parallel to the rolling direction of the sheet $[22,23]$. As shown in Fig. 2, the ISV model provided good correlation to the plastic flow stress of the AZ31 magnesium alloy.

In this study, all of the SPR simulations were conducted using axisymmetric 2D analysis in LS-dyna. The ISV material model described earlier is included in LS-dyna [24] and is listed as *MAT_BAMMAN (material mode type 51) and *MAT_BAMMAN_DAMAGE (material model type 52). To be consistent with the experiments by Wang et al., [5], a $0.35 \%$ carbon steel with $280 \mathrm{HV}$ was used by to represent the rivet material. An elastic-plastic material (*MAT_PIECEWISE_LINEAR_PLASTICITY), type 24 in LS-Dyna [24] was used for the rivet. Finally, the deformations of the pad, die and punch exhibit very low deflection compared to the 
rivet and sheets, and thus, were modeled as rigid bodies (*MAT_RIGID, type 20 in LS-Dyna [24]).

Typically, in solid mechanics, the Lagrangian formulation with uniform fixed element meshes is mainly used in FEA [6]. However, the drawback of this method is that, in large deformation simulations, elements may become very distorted, compromising the accuracy of the model. In order to avoid complications due to mesh disturbances and to capture the effect of the rivet piercing the sheet, the kill element technique was applied after damage of 0.99 is reached. In LS-Dyna 2D explicit, damage does not reach 0.99 due to numerical issues [25], and thus a erosion criterion is included in *MAT_BAMMAN_DAMAGE. As the damage value reaches 0.99 , the damage stiffness and yield of the element is $1 \%$ of the original values at the initial state. In fact, the strain-to-failure criterion must be large enough in order to eliminate elements that reached damage of 0.99 and sufficiently small to avoid high element distortion and numerical complications.

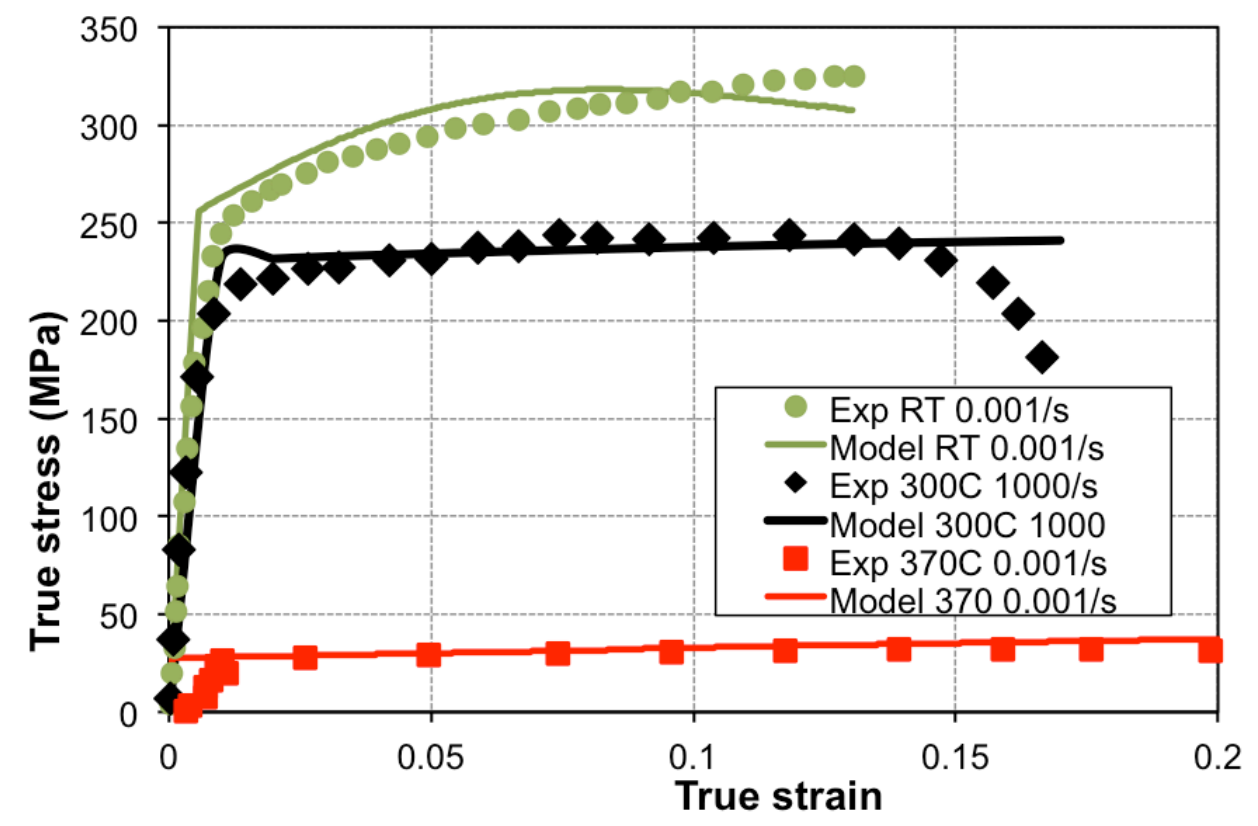

Figure 2. Comparison between the experimental and the BCJ model correlation results of a tensile test. 
In the current study, the Lagrangian method with an optimized mesh was used to decrease the time of the calculation. Since the SPR process can be approximated as axisymmetric problem, a four node 2D axisymmetric element was used, with four Gauss integration points and a stiffened based hourglass control (strain co-rotational stiffness form). Contact was modeled by applying *2D_AUTOMATIC-SURFACE_TO_SURFACE penalty formulation contained in LSDyna. Since the SPR analysis is dynamic, an explicit calculation mode was performed to model the piercing process. After the SPR process is completed, a springback and cooling step analysis was performed. As the material model used for magnesium cannot be applied in shell elements utilizing an implicit calculation, these two post-process calculations were performed using an explicit method, activated by *DYNAMIC_RELAXATION command in LS-Dyna.

As described elsewhere [5], the AZ31 magnesium alloy sheets were $2 \mathrm{~mm}$ in thickness. The geometric characteristics of the die (type DZ1002050H1R1.5) and rivet (K50642AH00) are show in Fig. 3 and the dimensional values are listed in Table 1. The punch has a radius of $4 \mathrm{~mm}$ and a height of $0.8 \mathrm{~mm}$. The pad has an outer radius of $9.25 \mathrm{~mm}$ and an inner radius of $5.45 \mathrm{~mm}$, and the bottom corners are rounded with a radius of $0.2 \mathrm{~mm}$. Regarding the SPR process, the clamping speed was $5 \mathrm{~mm} / \mathrm{second}$, the force applied on the holder to keep the sheets clamped was $600 \mathrm{~N}$, the riveting speed was $110 \mathrm{~mm} / \mathrm{s}$ and the riveting displacement was $6.25 \mathrm{~mm}$ downwards. Since the FEA model is axisymmetric, the clamped force is $600 \mathrm{~N}$ per unit radian. 


\section{RIVET}

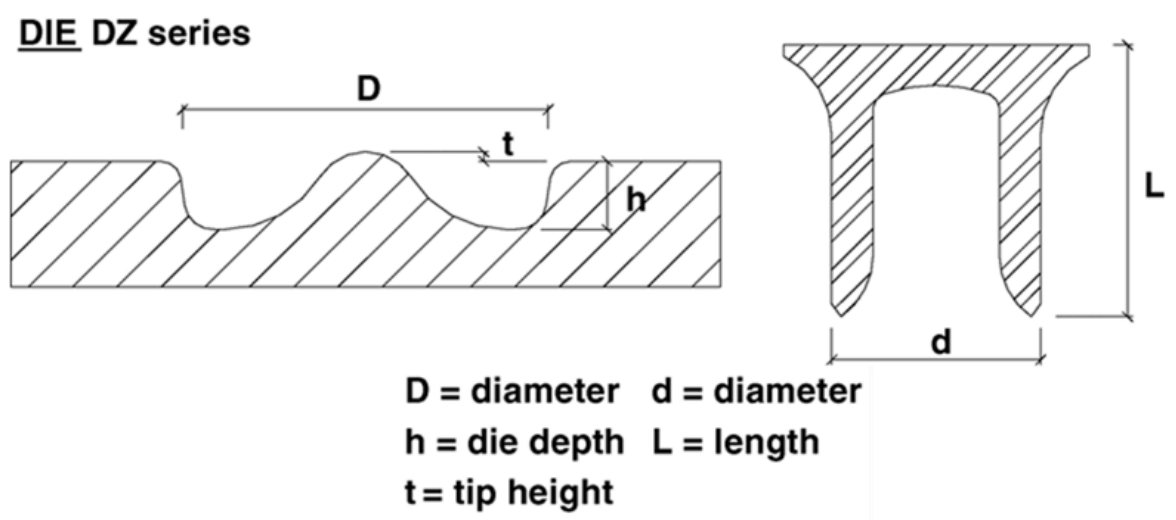

Figure 3. Self-pierce riveting die and rivet geometry [6]

Table 1. Dimensions of the self-pierce riveting die and rivet

\begin{tabular}{cccccc}
\hline Part & $\mathrm{D}(\mathrm{mm})$ & $\mathrm{h}(\mathrm{mm})$ & $\mathrm{t}(\mathrm{mm})$ & $\mathrm{d}(\mathrm{mm})$ & $\mathrm{L}(\mathrm{mm})$ \\
\hline Rivet & - & - & - & 5 & 6 \\
Die & 10 & 1.5 & 0.25 & - & - \\
\hline
\end{tabular}

The initial configuration of the finite element simulation of the SPR process is shown in Fig. 4. The size of the smallest element in the sheets and the rivet is $0.1 \mathrm{~mm} \times 0.1 \mathrm{~mm}$, as this was selected since Porcaro et al. [6] showed it gives a reasonable accuracy in the SPR simulations. In this configuration the entire model is composed by 5455 shell elements totaling 5903 nodes. Employing a finer mesh such as $0.05 \mathrm{~mm} \times 0.05 \mathrm{~mm}$ in the large deformation area, resulted in 12535 elements and 13103 nodes, which increased the calculation time by about 15 times with relatively no change in accuracy compared to $0.1 \mathrm{~mm} \times 0.1 \mathrm{~mm}$ mesh. Thus, the 0.1 $\mathrm{mm} \times 0.1 \mathrm{~mm}$ mesh was used in this study. 
The choice of the coefficient of friction (CF) in any FEA involving contact has a large influence in the total deformation. In fact, parameters such as temperature, pressure and velocity drastically influence the CF between steel and AZ31 magnesium alloy sheets [26] and previous SPR simulations have shown strong influence on the choice of the coefficient of friction and final deformation $[6,9]$. However, in this study, an attempt was made to avoid letting the choice of CF to become a fitting parameter of the simulations. As such, we elected, possibly to the detriment of our simulation results, to use values that were closely related to experimental results. The choice of the friction was taken as a reference from Bolz \& Tuve [27] and Ceretti et al. [28]. Thus, the coefficients used in this study are essentially based on physical parameters.

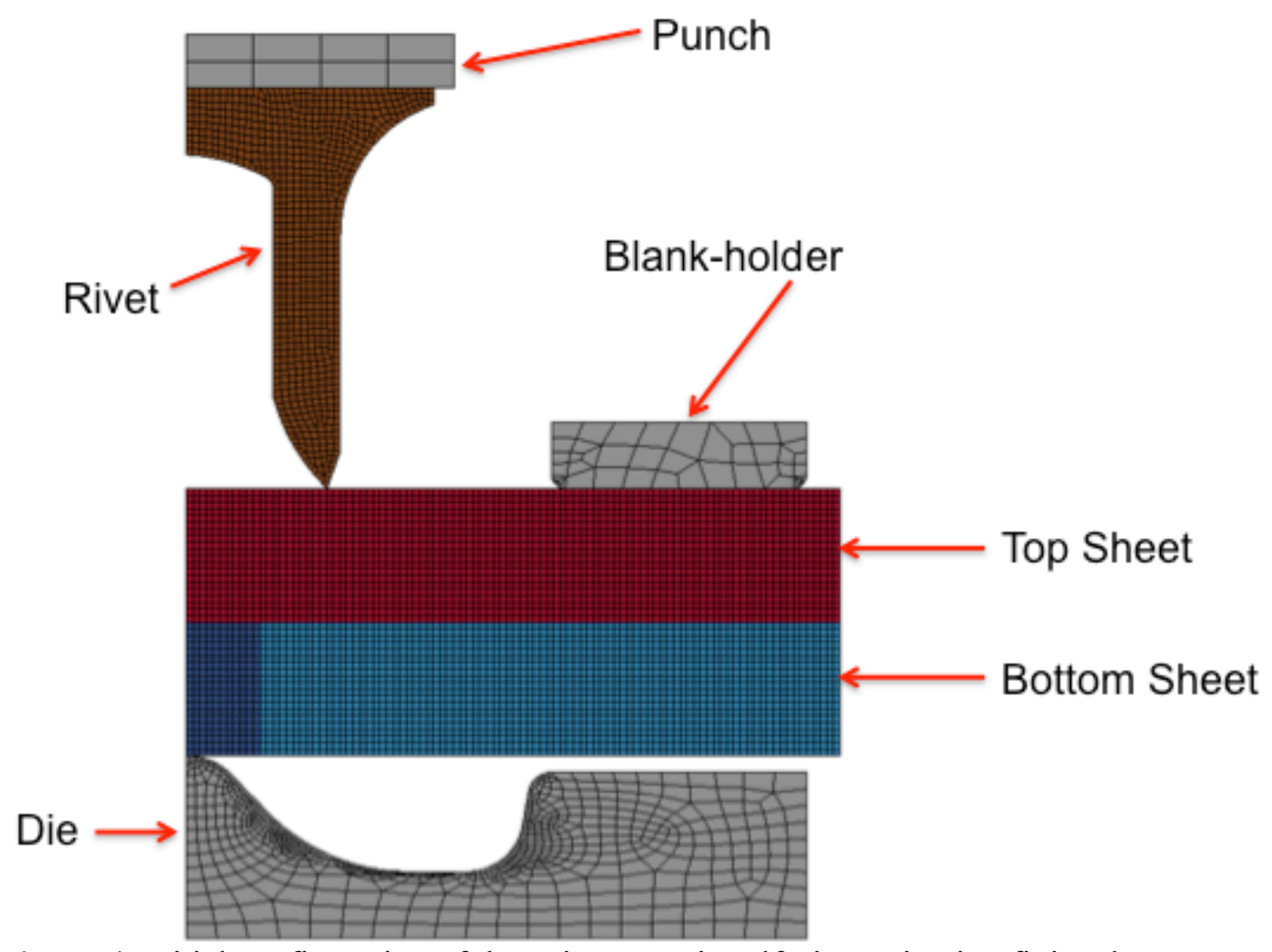

Figure 4. Initial configuration of the axisymmetric self-pierce riveting finite element model. 
In addition, we note, that since the SPR process did not match exactly to the boundary conditions of the Bolz \& Tuve [27] and Ceretti et al. [28], some variations were estimated taking into account change in temperature, pressure and velocity. Table 2 lists the CFs used in all of the simulations performed in this study. However, we acknowledge that future work in FEA of SPR should include CFs determined through experimental work with the same conditions as the SPR process. This could be done by conducting a pin-on-disk experiment using a pin made of steel and an AZ31 magnesium alloy disk at different temperatures, normal pressures and velocities similar to Ceretti E. et al. [28].

In this study, the following type of simulations using the ISV material model were performed at initial temperature of $200^{\circ} \mathrm{C}$ : (a) isothermal with a strain-to-failure based killelement criterion correlated to experimental tensile tests (55\% strain-to-failure [5]), (b) isothermal and strain-to-failure based kill-element criterion equal to $250 \%$ strain for top sheet, where this strain value was obtained via trial and error; (c) isothermal and strain-to-failure based kill-element criterion equal to $250 \%$ strain for both top and bottom sheets; d) adiabatic and strain-to-failure based kill-element criterion equal to $250 \%$ strain for on top sheet; e) adiabatic, kill-element criterion based damage reaching 0.99 on top sheet only; f) adiabatic, kill-element criterion based damage reaching 0.99 on both the top and bottom sheets. Springback analysis was performed on all of the simulations using a dynamic relaxation in explicit mode. We note that others have performed springback using an implicit approach. However, implicit implementation is not compatible with BCJ and shell elements in LS-dyna. Thus, we used a less common approach employing dynamic relaxation in an explicit code. 
Table 2. Coefficients of friction (CF) values used for the simulations in this study

\begin{tabular}{ccc}
\hline Parts & \multicolumn{3}{c}{ Coefficient of Friction } \\
& Static & Dynamic \\
\hline Pad/Sheets & 0.6 & 0.5 \\
Die/Sheets & 0.6 & 0.5 \\
Rivet/Sheets & 0.15 & 0.12 \\
Sheet/Sheet & 0.7 & 0.45 \\
\hline
\end{tabular}

This explicit method has been used in other springback calculations in prior work, but not in any of the SPR simulation results shown in literature. Our springback simulations show that that the overall shape after springback and cool down period does not significantly change the final shape of the joint. 


\section{RESULTS AND DISCUSSION}

The application of SPR in Mg alloys is a complex large-scale rate and temperature dependent boundary value problem. As observed by Wang et al. [5] and elsewhere, the material during the riveting process experiences high strain rate, and physically observed temperature increase. As such, we selected the BCJ model, since the model was developed for these types of problems by capturing the physics and mechanics of large-scale plasticity, with the capability to significantly affect the strain to failure due to the inclusion of adiabatic heat generation. Figure 5 shows the an example of the SPR process at different time steps, showing effective stress (Fig. 5a) and effective strain (Fig. 5b) in both sheets. This image was obtained from the simulation with the following configuration: adiabatic, kill-element criterion based damage reaching 0.99 on both the top and bottom sheets. As the stresses in the rivet are much higher than the ones in the $\mathrm{Mg}$ sheets, the stress and strain shown are only for the Mg sheets. The comparison of the FEA results of this study are taken from the post-processing of the LS-dyna simulations. To make the comparison, springback and cooling are performed after the SPR process, so the outline of the FEA shape is superimposed on an image of the cross-section of the experimentally created joint, as shown in Fig. 5c [5]. To further aid in illustrating the stress and strain development in the SPR process, Video 1 and Video 2 show the complete time interval of the effective stress and effective strain evolution, respectively. 


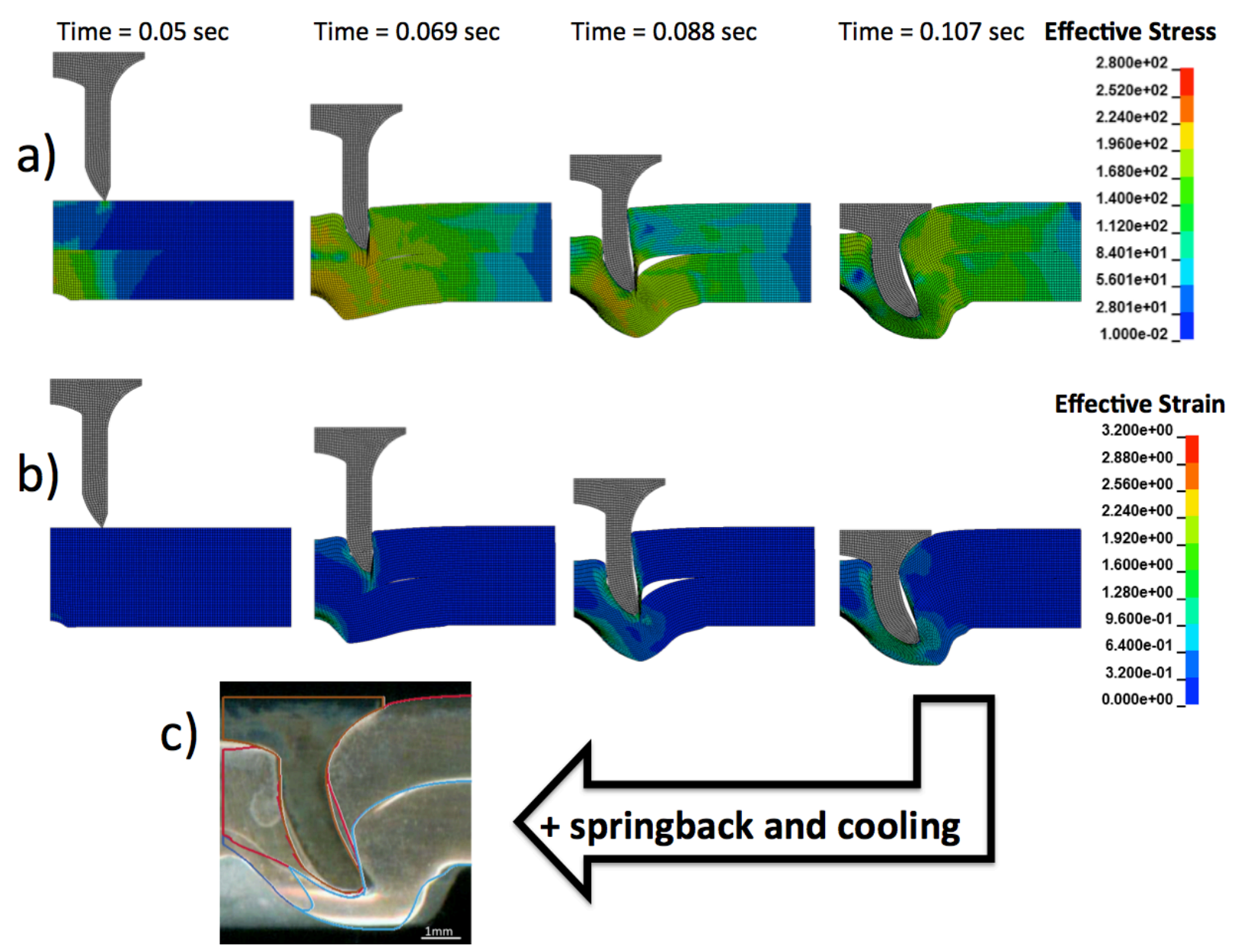

Figure 5. The self-pierce riveting process at different time steps: a) effective stress, b) effective strain, c) final shape of the FEA superimposed on the experimental results.

In order to illustrate the complexity of including damage in finite element analysis, visual evaluation of the FEA results with different configurations as described in the previous section, are compared to an image of the cross-section of the experimentally created joint [5] . Fig. 6a shows comparison of the isothermal SPR simulation using a simple tensile data obtained from Wang et al. [5] of AZ31 magnesium alloy at a temperature $200^{\circ} \mathrm{C}$ and strain rate of $4.1 / \mathrm{s}$. As shown in Fig. 6a, the choice of a strain-to-failure of 55\% produces a significantly unsatisfactory comparison to the experimental results. In fact, the kill-element criterion essentially eliminates the elements to soon, leading to a relatively brittle-like deformation not observed experimentally. 
Figure $6 \mathrm{~b}$ shows the visual evaluation of the SPR simulation with a strain-to-failure criterion chosen by trial-and-error $(250 \%)$. In these simulations, the strain-to-failure was only applied to the top sheet and no damage was allowed to develop in the bottom sheet. As the strain-to-failure of $250 \%$ is significantly greater than the uniaxial tensile strain for this material at this temperature, it further illustrates the unsuitability of using uniaxial tensile strain to predict failure in a complex boundary value problem. For additional comparisons, the strain-to-failure criterion was applied to both the top and bottom sheets. As shown in Fig. 6c, using strain-tofailure criteria in the bottom sheet caused excessive softening of the bottom sheet leading to a reduction in the spreading of the rivet.

Figure $6 \mathrm{~d}$, e, and $\mathrm{f}$, illustrate the results of allowing for heat generation during the deformation. Fig. $6 \mathrm{~d}$ shows the results of using adiabatic and strain-to-failure of $250 \%$ on the top sheet only. The most obvious difference resulting from the inclusion of adiabatic heat generation in this simulation, was the gaps between the rivet and the sheets were largely eliminated. Fig. 6e shows the results of using adiabatic and the kill-element criterion based on damage reaching 0.99 on the top sheet only. In this simulation result, the gap between the rivet and the top sheet are also minimized. The main difference observed between the using as strainto-failure and the kill-element criterion based on damage reaching 0.99 is the small amount of material underneath the rivet leg. In the strain-to-failure simulations (Fig. 6d), a majority of the elements of the top sheet just under the rivet leg are eliminated due to the uniform strain-tofailure criterion. However, in the simulations using the kill-element criterion based on damage reaching 0.99, a more representative amount of elements remain in the simulation similar to what is shown by the actual rivet. 



Figure 6. Comparison between numerical analysis and experimental results [5] for of the final shape of the SPR: a) isothermal and strain to failure based on uniaxial tensile results $(55 \%)$; b) isothermal, strain to failure of $250 \%$ on top sheet; c) Isothermal and strain to failure of $250 \%$ on top and bottom sheets; d) adiabatic, strain to failure of $250 \%$ on top sheet; e) adiabatic and failure based on damage criterion on top sheet; $f$ ) adiabatic and failure based on damage criterion on top and bottom sheets. Experimental images adapted from [5].

In order to model the both the top and bottom sheet in a more physically representative approach, the bottom sheet was not shielded from damage, but allowed to evolve naturally. Figure $6 f$ shows the results of using the kill-element criterion based on damage reaching 0.99 in both the top and bottom sheets. This simulation did not compare as well to the experimental results as of damage only in the top sheet. We further note, that the asymmetry of the AZ31 $\mathrm{Mg}$ alloy caused some difficulty in using the kill-element criterion based on damage reaching 0.99 in the bottom sheet. In fact, while not shown, simulation results showed that an excessive damage 
rate was leading to premature softening not observed in the experimental results. As such, the damage growth rate was calibrated with a different value for the compression due to the asymmetry observed between tension and compression in magnesium alloy. The darker region of the bottom sheet in Fig. 4 was assigned a damage rate that allowed for larger elongation observed for Mg alloy under compression loading. The remainder of the bottom sheet was assigned the identical damage rate as the top. Using this anisotropic damage mapping, no elements of the bottom sheet reached a damage of 0.99 .

To illustrate how temperature and stresses change during the SPR process, temperature and von Mises stress history plots taken from an element the top sheet near the vicinity of the rivet is presented in Fig. 7. The inclusion of heat generation in the plastic deformation is essential for accurately capturing the flow stress in the SPR simulation. In fact, Fig. 7a shows that for the element selected, for instance, a $160^{\circ} \mathrm{C}$ temperature increase was observed due to the large deformation. This large increase in temperature resulted in a decrease in the stress carried by this element of about $100 \mathrm{MPa}$, as shown Fig. 7c. While these values are based on simulation results, we have illustrated the importance of including heat generation.

To evaluate the ability to predict cracks with ISV and damage model, and additional simulation was run (Fig. 8a) at an initial temperature of $25^{\circ} \mathrm{C}$, with the adiabatic material model and damage applied on both top and bottom sheets, so the only parameter changed was the initial temperature of the sheets. The black elements in Fig. 8a were killed from the simulation and their location is shown in the deformed and final configuration of the joint. Figure $8 \mathrm{~b}$ illustrates that the model predicted the onset of a crack in the same location compared to the experimental results shown in Fig. 8c. 

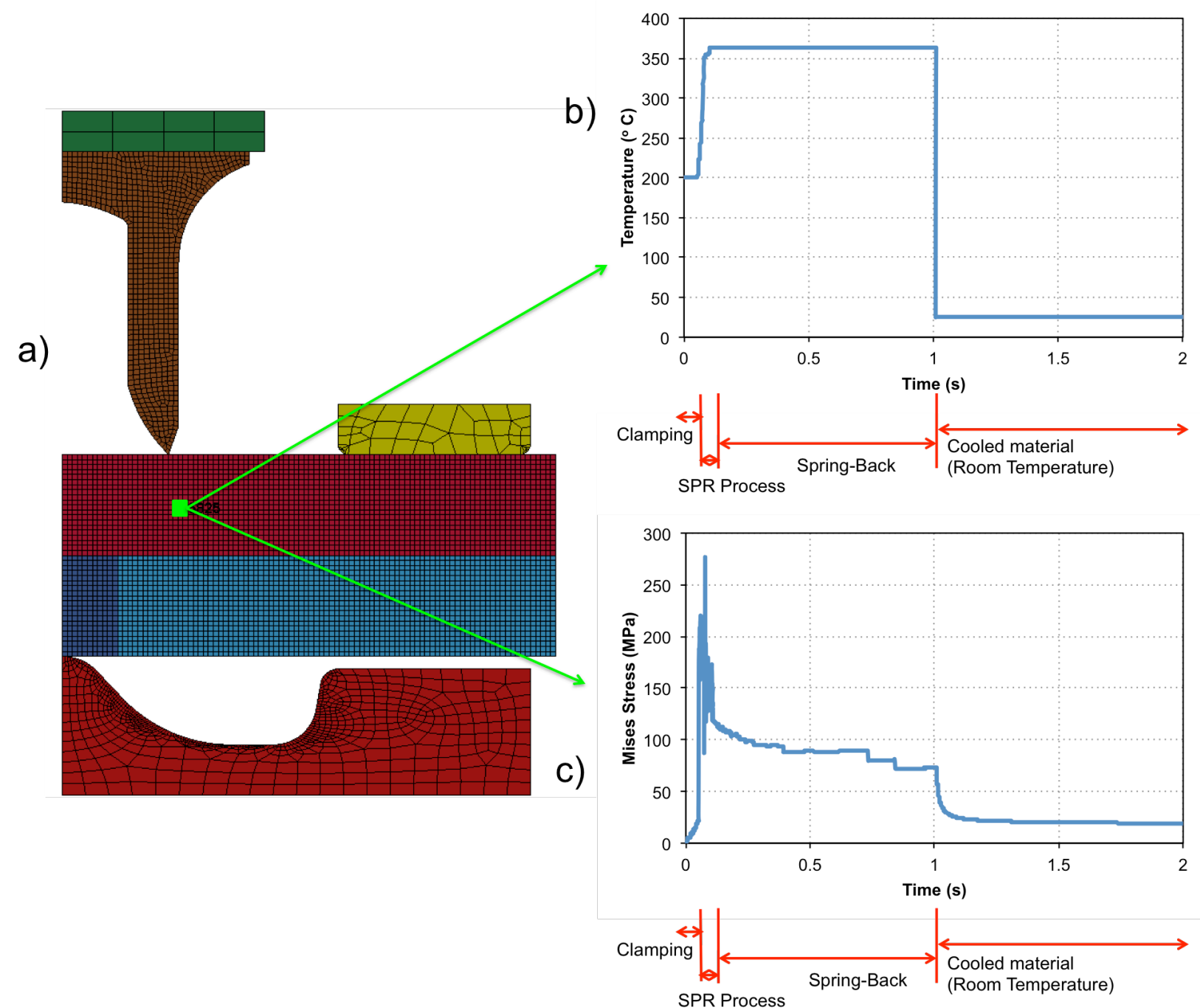

Figure 7. History plot of one element from top sheet: a) element selected in green; b) temperature; c) von Mises Stress. 


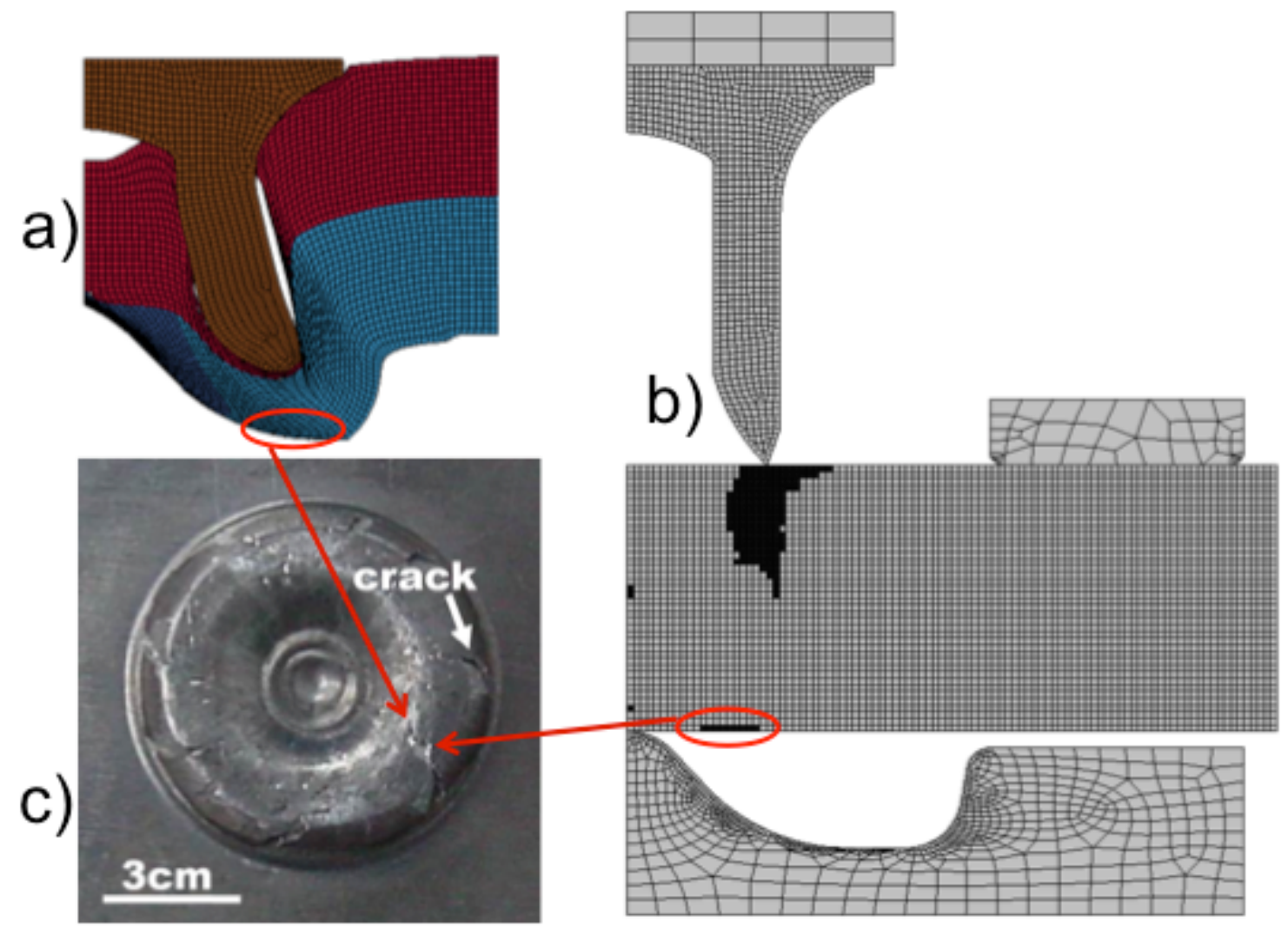

Figure 8. Comparison between numerical analysis and experimental results showing crack prediction at room temperature for SPR of Mg alloy: a) Location of the elements deleted on the final configuration of the joint during the simulation, b) elements deleted from [5]).

The use of the BCJ plasticity model appears to satisfactorily capture the complex nature of isotropic and kinematic hardening and recovery. In fact, we make the argument that the use of ISV models is likely a more computationally efficient and physically motivated approach to model the SPR process compared to other approaches. It is the combination of the hardening and recovery plastic flow rule coupled with heat generation that captures the deformation of SPR. Moreover, the BCJ model appears to adequately capture the large deformation without the need to remesh. This is a significant point, since remeshing algorithms can produce errors as large as 50\%. More importantly, the advantage of not re-meshing is that that stress histories of 
the elements remain in tact, resulting in the application of a stress-based damage criterion for material fracture.

While we acknowledge that others have produced good comparisons between simulations without an element deletion criterion, we have attempted to model the experimental results using a more physically accurate approach that models the damage model evolution. While the simulations results compared well to the experimental shape of the SPR with both strain-tofailure and damage model including adiabatic, we note that the simulation results with the damage model produced results that were less accurate in terms of final shape of the riveted join. The experiments required to adequately evaluate the triaxialty include notched tensile tests with a range of notch radii at various strain rates and temperatures. Unfortunately, we were unable to find data in literature on notched tensile tests at the required strain rates and temperature. This largely is a result that this type of experiment is very difficult to perform using a split Hopkinson bar test. Thus, we acknowledge that to truly calibrate the damage model, an extensive modeling and experimental effort is required, which is beyond the scope of this paper. Lastly we acknowledge that the BCJ model employed in this study does not explicitly address deformation due to twinning. However, at the ideal temperature $\left(200^{\circ} \mathrm{C}\right)$ for performing $\mathrm{SPR}$ in $\mathrm{Mg}$ alloys, twinning is not activated and thus the flow rule of the BCJ is a valid assumption at elevated temperatures. Future modeling development of the BCJ model for HCP metals should include flow rules specifically for the deformation associated with twinning mechanisms. 


\section{SUMMARY AND CONCLUSIONS}

Self-piecing riveting is a forming process in which a rivet, pressed by a punch, pierces the top sheet and flares into the bottom sheet, resulting in a mechanical interlock between the sheets. In the case of self-pierce riveting AZ31 magnesium sheets, the process must be conducted at elevated temperatures in order to produce a good joint due to the low ductility of this material at low temperatures. Numerical simulations of the SPR process were carried out using the commercial code LS-Dyna. The 2D axisymmetric model was composed of the rivet, two sheets, die, blank holder and punch. An explicit solution technique was applied and riveting through the top sheet was possible because of the use of a damage model and element deletion criterion.

For the first time, use of an internal state variable (ISV) plasticity and damage model was successfully applied to capture the complex deformation observed in the SPR. Good agreement was observed by visual comparison of the final geometry of the simulation and the experimental results. We further note that the good correlation of the deformation was achieved without remeshing techniques used elsewhere in literature. Furthermore, the ISV model was shown to produce favorable predictions of cracks under room temperature riveting. Since the use of this ISV model is shown as a feasible method for modeling the SPR process, future simulation work could focus on different temperatures and punch velocities. In addition, this model could be used to check the feasibility of using aluminum rivets on magnesium sheets, resulting in a joint with better corrosive behavior. In addition, non-local methods should possibly be considered when damage or strain localization is present [29]. 


\section{REFERENCES}

[1] Atzeni E., Ippolito R., and Settineri L., 2009, "Experimental and numerical appraisal of self-piercing riveting," CIRP Annals - Manufacturing Technology, 58(1), pp. 17-20.

[2] Barnes, T. A., and Pashby I. R., 2000, "Joining Techniques for Aluminum Spaceframes Used in Automobiles Part II-Adhesive Bonding and Mechanical Fasteners," J. Mater. Process. Technol., 99, pp. 72-79.

[3] Yan, J., Xu, Z., and Li Z., 2005, "Microstructure Characteristics and Perform- ance of Dissimilar Welds Between Magnesium Alloy and Aluminum Formed by Friction Stirring," Scr. Mater., 53, pp. 585-589.

[4] Czerwinski F., 2011, "Welding and Joining of Magnesium Alloys," Magnesium Alloys Design, Processing and Properties, pp. 469-491.

[5] Wang J. W., Liu Z. X., Shang Y., Liu a. L., Wang M. X., Sun R. N., and Wang P.-C., 2011, "Self-Piercing Riveting of Wrought Magnesium AZ31 Sheets," Journal of Manufacturing Science and Engineering, 133(3), p. 031009.

[6] Porcaro R., Hanssen a. G., Langseth M., and Aalberg a., 2006, "Self-piercing riveting process: An experimental and numerical investigation," Journal of Materials Processing Technology, 171(1), pp. 10-20.

[7] He X., Pearson I., and Young K., 2008, "Self-pierce riveting for sheet materials: State of the art," Journal of Materials Processing Technology, 199(1-3), pp. 27-36.

[8] Durandet Y., Deam R., Beer a., Song W., and Blacket S., 2010, "Laser assisted self-pierce riveting of AZ31 magnesium alloy strips,” Materials \& Design, 31, pp. S13-S16.

[9] Casalino G., Rotondo a., and Ludovico a., 2008, "On the numerical modelling of the multiphysics self piercing riveting process based on the finite element technique," Advances in Engineering Software, 39(9), pp. 787-795.

[10] Krishnapp U. S., 2008, "Numerical investigation of self-piercing riveted dual layer joint," Wichita State University.

[11] Bijju M., 2010, "Failure analysis of self-piercing riveted joint under different loading conditions using finite element method," Wichita State University. 
[12] Bammann D. ., 1984, “An Internal Variable Model of Viscoplasticity,” Int. J. Eng. Sci., 22(8), pp. 1041-1053.

[13] Bammann D., and Aifantis E. C., 1989, "A damage model for ductile metals," Nuclear engineering and design, 116, pp. 355-362.

[14] Bammann D. J., Chiesa M. L., and Johnson G. C., 1996, "Modeling large deformation and failure in manufacturing processes,” Theor. Appl. Mech., T. Tatsumi, E. Wannabe, and T. Kambe, eds., pp. 256-276.

[15] Horstemeyer M., and Gokhale A., 1999, "A void-crack nucleation model for ductile metals," International Journal of Solids and Structures, 36, pp. 5029-5055.

[16] Marin E. B., Bammann D. J., Regueiro R. A., and Johnson G. C., 2006, On the Formulation, Parameter Identification and Numerical Integration of the EMMI Model : Plasticity and sotropic Damage;Sandia Report SAND2006-0200.

[17] Horstemeyer M. F., 2001, From atoms to autos: a new design paradigm using microstructure-property modeling. Part 1: Monotonic loading conditions.

[18] Horstemeyer M. F., and Wang P., 2004, "Cradle-to-grave simulation-based design incorporating multiscale microstructure-property modeling: Reinvigorating design with science," Journal of Computer-Aided Materials Design, 10, pp. 13-34.

[19] Jordon J. B., Horstemeyer M. F., Solanki K., and Xue Y., 2007, "Damage and stress state influence on the Bauschinger effect in aluminum alloys," Mechanics of Materials, 39(10), pp. 920-931.

[20] Cocks A. C. F., and Ashby M. F., 1980, “Intergranular fracture during power-law creep under multiaxial stresses,” Metal Science, 14(8-9), pp. 8-9.

[21] Cocks A. C. F., and Ashby M. F., 1982, "On creep fracture by void growth," Progress in Materials Science, 27(3-4), pp. 189-244.

[22] Hasenpouth D., 2010, “Tensile High Strain Rate Behavior of AZ31B Magnesium Alloy Sheet," University of Waterloo.

[23] Wu H., Sun P., and Lin F., 2011, "Anisotropic and tensile flow behaviors of Mg alloy AZ31B thin sheet in H24 condition at elevated temperatures," Materials Science and Engineering: A, 528(6), pp. 2522-2531.

[24] Livermore Software Technology Corporation, 2012, "Keyword user’s manual."

[25] Bammann D. ., Chiesa M. ., Horstemeyer M. F., and Weingarten L. ., 1993, "Failure in ductile material using finite element methods," Structural Crashworthiness and Failure, N. Jones, and T. Weirzbicki, eds., pp. 1-52. 
[26] Ceretti E., Fiorentino a., and Giardini C., 2008, "Process parameters influence on friction coefficient in sheet forming operations," International Journal of Material Forming, 1(S1), pp. 1219-1222.

[27] Bolz R. E., and Tuve G. L., 1973, CRC Handbook of Tables for Applied Engineering Science.

[28] Ceretti E., Fiorentino a., and Giardini C., 2008, "Process parameters influence on friction coefficient in sheet forming operations," International Journal of Material Forming, 1(S1), pp. 1219-1222.

[29] Ahad F. R., Enakoutsa K., Solanki K. N., and Bammann D. J., 2013, "Nonlocal modeling in high-velocity impact failure of 6061-T6 aluminum," International Journal of Plasticity, pp. 1-25. 
APPENDIX A. ADDITIONAL ISV MODEL EQUATIONS

$$
\begin{aligned}
& V(T)=C_{1} \exp \left(-C_{2} / T\right) \\
& Y(T)=C_{3} \exp \left(C_{4} / T\right) \\
& f(T)=C_{5} \exp \left(-C_{6} / T\right) \\
& r_{d}(T)=C_{7} \exp \left(-C_{8} / T\right) \\
& h(T)=C_{9} \exp \left(C_{10} / T\right) \\
& r_{s}(T)=C_{11} \exp \left(-C_{12} / T\right) \\
& R_{d}(T)=C_{13} \exp \left(-C_{14} / T\right) \\
& H(T)=C_{15} \exp \left(C_{16} / T\right) \\
& R_{17} \exp \left(-C_{18} / T\right)
\end{aligned}
$$


APPENDIX B. SAMPLE KEYWORD USED FOR SELF-PIERCE RIVETING PROCESS IN LS-DYNA

${ }^{*} K E Y W O R D$

*TITLE

\$\# title

LS-DYNA keyword deck by LS-PrePost

${ }^{*}$ CONTROL_BULK_VISCOSITY

\$\# q1 q2 type btype

$\begin{array}{llll}1.500000 & 0.060000 & 1 & 0\end{array}$

*CONTROL_CONTACT

\$\# slsfac rwpnal islchk shlthk penopt thkchg orien enmass

$\begin{array}{llllllll}0.300000 & 0.000 & 1 & 2 & 4 & 1 & 1 & 0\end{array}$

\$\# usrstr usrfrc nsbcs interm xpene ssthk ecdt tiedprj

$\begin{array}{llllllll}0 & 0 & 0 & 0 & 4.000000 & 0 & 0 & 0\end{array}$

$\$ \#$ sfric dfric edc vfc th th_sf pen_sf

$\begin{array}{lllllll}0.000 & 0.000 & 0.000 & 0.000 & 0.000 & 0.000 & 0.000\end{array}$

\$\# ignore frceng skiprwg outseg spotstp spotdel spothin

$\begin{array}{lllllll}0 & 0 & 0 & 0 & 0 & 0 & 0.000\end{array}$

\$\# isym nserod rwgaps rwgdth rwksf icov swradf ithoff

$\$ \#$ shledg

0

${ }^{*}$ CONTROL_ENERGY

\$\# hgen rwen slnten rylen

$\begin{array}{llll}1 & 2 & 1 & 1\end{array}$

${ }^{*}$ CONTROL_HOURGLASS

$\$ \#$ inq qh

60.150000

*CONTROL_SHELL

\$\# wrpang esort irnxx istupd theory bwc miter proj

$\begin{array}{llllllll}20.000000 & 0 & -1 & 1 & 15 & 2 & 2 & 0\end{array}$

$\$ \#$ rotascl intgrd lamsht cstyp6 tshell nfail1 nfail4 psnfail

$\begin{array}{llllllll}1.000000 & 0 & 0 & 1 & 0 & 0 & 0 & 0\end{array}$

\$\# psstupd irquad cntco itsflg irquad

${ }^{*}$ CONTROL_TERMINATION

\$\# endtim endcyc dtmin endeng endmas

$\begin{array}{lllll}0.107000 & 0 & 0.000 & 0.000 & 0.000\end{array}$

${ }^{*}$ CONTROL_TIMESTEP

$\$ \#$ dtinit tssfac isdo tslimt dt2ms lctm erode ms1st $\begin{array}{llllllll}0.000 & 0.900000 & 0 & 0.000 & 0.000 & 0 & 0 & 0\end{array}$ 
\$\# dt2msf dt2mslc imscl

$\begin{array}{lll}0.000 & 0 & 0\end{array}$

*DATABASE_BINARY_D3PLOT

$\$ \#$ dt Icdt beam npltc psetid

$\begin{array}{lllll}5.0000 \mathrm{E}-4 & 0 & 0 & 0 & 0\end{array}$

$\$ \#$ ioopt

0

*DATABASE_EXTENT_BINARY

\$\# neiph neips maxint strflg sigflg epsflg rltflg engflg $\begin{array}{llllllll}35 & 35 & 3 & 1 & 1 & 1 & 1 & 1\end{array}$

\$\# cmpflg ieverp beamip dcomp shge stssz n3thdt ialemat $\begin{array}{llllllll}0 & 0 & 0 & 1 & 1 & 1 & 2 & 1\end{array}$

\$\# nintsld pkp_sen sclp unused msscl therm intout nodout $\begin{array}{llllll}0 & 0 & 1.000000 & 0 & 0 & \text { OSTRESS }\end{array}$

*BOUNDARY_PRESCRIBED_MOTION_RIGID_ID

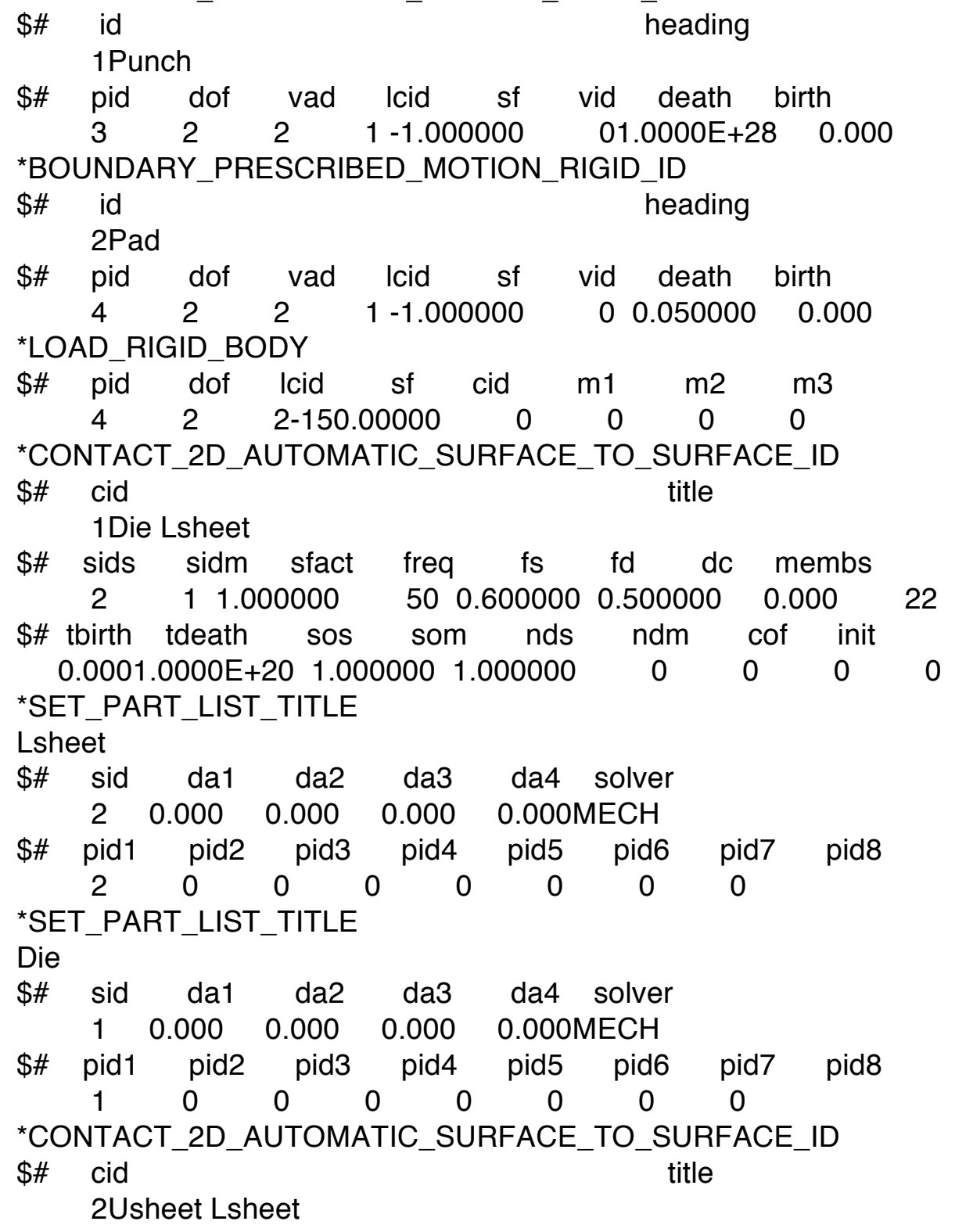


\$\# sids sidm sfact freq fs fd dc membs $\begin{array}{llllllll}2 & 6 & 1.000000 & 50 & 0.700000 & 0.450000 & 0.000 & 22\end{array}$

\$\# tbirth tdeath sos som nds ndm cof init

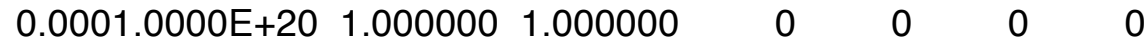

*SET_PART_LIST_TITLE

Usheet

$\$ \#$ sid da1 da2 da3 da4 solver

$\begin{array}{lllll}6 & 0.000 & 0.000 & 0.000 & 0.000 \mathrm{MECH}\end{array}$

$\$ \#$ pid1 pid2 pid3 pid4 pid5 pid6 $\begin{array}{llllllll}6 & 0 & 0 & 0 & 0 & 0 & 0 & 0\end{array}$

*CONTACT_2D_AUTOMATIC_SURFACE_TO_SURFACE_ID

$\$ \#$ cid 3Pad Usheet

\$\# sids sidm sfact freq fs fd dc membs

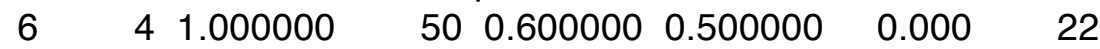

$\$ \#$ tbirth tdeath sos som nds ndm cof init $\begin{array}{lllllll}0.0001 .0000 E+20 & 1.000000 & 1.000000 & 0 & 0 & 0 & 0\end{array}$ ${ }^{*}$ SET_PART_LIST_TITLE

Pad

\$\# sid da1 da2 da3 da4 solver

$\begin{array}{lllll}4 & 0.000 & 0.000 & 0.000 & 0.000 \mathrm{MECH}\end{array}$

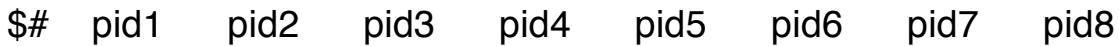
$\begin{array}{llllllll}4 & 0 & 0 & 0 & 0 & 0 & 0 & 0\end{array}$

${ }^{*}$ CONTACT_2D_AUTOMATIC_SURFACE_TO_SURFACE_ID

$\$ \#$ cid title

4Rivet Usheet

\$\# sids sidm sfact freq fs fd dc membs $\begin{array}{llllllll}6 & 5 & 1.000000 & 50 & 0.150000 & 0.120000 & 0.000 & 22\end{array}$

$\$ \#$ tbirth tdeath sos som nds ndm cof init $\begin{array}{lllllll}0.0001 .0000 E+20 & 1.000000 & 1.000000 & 0 & 0 & 0 & 0\end{array}$ *SET_PART_LIST_TITLE

Rivet

$\$ \#$ sid da1 da2 da3 da4 solver $\begin{array}{lllll}5 & 0.000 & 0.000 & 0.000 & 0.000 \mathrm{MECH}\end{array}$

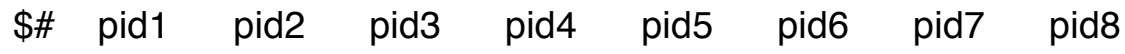
$\begin{array}{llllllll}5 & 0 & 0 & 0 & 0 & 0 & 0 & 0\end{array}$

*CONTACT_2D_AUTOMATIC_SURFACE_TO_SURFACE_ID

$\$ \#$ cid title 5Rivet Lsheet

$\$ \#$ sids sidm sfact freq fs fd dc membs

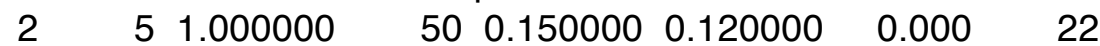

\$\# tbirth tdeath sos som nds ndm cof init $\begin{array}{lllllll}0.0001 .0000 E+20 & 1.000000 & 1.000000 & 0 & 0 & 0 & 0\end{array}$ *CONTACT_2D_AUTOMATIC_SURFACE_TO_SURFACE_ID $\$ \#$ cid title 6Punch Rivet

\$\# sids sidm sfact freq fs fd dc membs

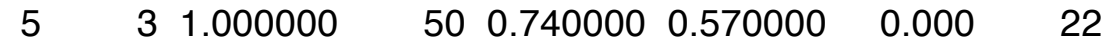

$\$ \#$ tbirth tdeath sos som nds ndm cof init 


$$
\begin{array}{lllllll}
0.0001 .0000 E+20 & 1.000000 & 1.000000 & 0 & 0 & 0 & 0
\end{array}
$$

*SET_PART_LIST_TITLE

Punch

\$\# sid da1 da2 da3 da4 solver

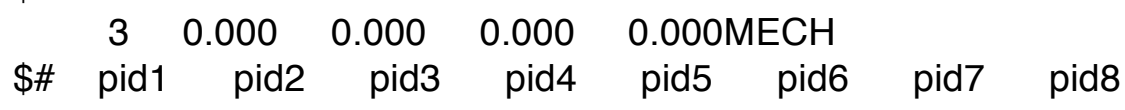
$\begin{array}{llllllll}3 & 0 & 0 & 0 & 0 & 0 & 0 & 0\end{array}$

${ }^{*}$ CONTACT_2D_AUTOMATIC_SURFACE_TO_SURFACE_ID

$\$ \#$ cid title

7Usheet Usheet

\$\# sids sidm sfact freq fs fd dc membs

$\begin{array}{llllllll}6 & 6 & 1.000000 & 50 & 0.700000 & 0.450000 & 0.000 & 22\end{array}$

$\$ \#$ tbirth tdeath sos som nds ndm cof init $\begin{array}{lllllll}0.0001 .0000 E+20 & 1.000000 & 1.000000 & 0 & 0 & 0 & 0\end{array}$

${ }^{*}$ CONTACT_2D_AUTOMATIC_SURFACE_TO_SURFACE_ID

$\$ \#$ cid

title

8Lsheet Lsheet

\$\# sids sidm sfact freq fs fd dc membs

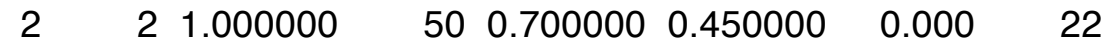

$\$ \#$ tbirth tdeath sos som nds ndm cof init $\begin{array}{lllllll}0.0001 .0000 E+20 & 1.000000 & 1.000000 & 0 & 0 & 0 & 0\end{array}$ *CONTACT_2D_AUTOMATIC_SURFACE_TO_SURFACE_ID

$\$ \#$ cid title 9Lsheet compression Lsheet

\$\# sids sidm sfact freq fs fd dc membs

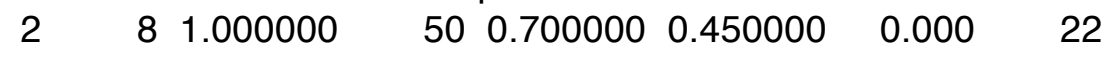

$\$ \#$ tbirth tdeath sos som nds ndm cof init $\begin{array}{lllllll}0.0001 .0000 \mathrm{E}+20 & 1.000000 & 1.000000 & 0 & 0 & 0 & 0\end{array}$ *SET_PART_LIST_TITLE bottom Compression

$\$ \#$ sid da1 da2 da3 da4 solver $\begin{array}{lllll}8 & 0.000 & 0.000 & 0.000 & 0.000 \mathrm{MECH}\end{array}$

$\$ \#$ pid1 $\quad$ pid2 pid3 pid4 $\begin{array}{llllllll}7 & 0 & 0 & 0 & 0 & 0 & 0 & 0\end{array}$

*CONTACT_2D_AUTOMATIC_SURFACE_TO_SURFACE_ID

$\$ \#$ cid title 10Lsheet compression Usheet

\$\# sids sidm sfact freq fs fd dc membs

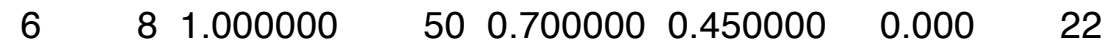

\$\# tbirth tdeath sos som nds ndm cof init $\begin{array}{lllllll}0.0001 .0000 E+20 & 1.000000 & 1.000000 & 0 & 0 & 0 & 0\end{array}$ ${ }^{*}$ CONTACT_2D_AUTOMATIC_SURFACE_TO_SURFACE_ID \$\# cid title 11Lsheet compression Lsheet comression

\$\# sids sidm sfact freq fs fd dc membs $\begin{array}{llllllll}8 & 8 & 1.000000 & 50 & 0.700000 & 0.450000 & 0.000 & 22\end{array}$ $\$ \#$ tbirth tdeath sos som nds ndm cof init

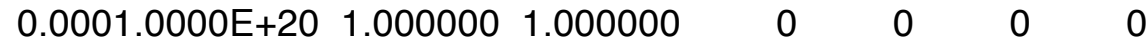
*CONTACT_2D_AUTOMATIC_SURFACE_TO_SURFACE_ID 


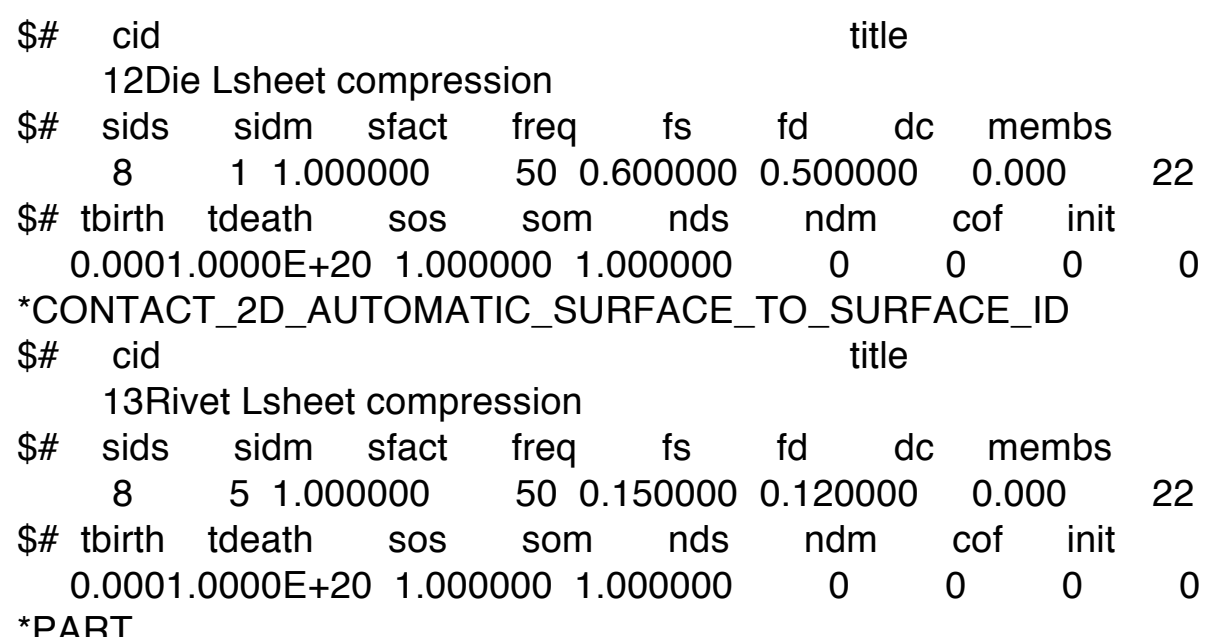

$\$ \#$ title

Die

\$\# pid secid mid eosid hgid grav adpopt tmid $\begin{array}{llllllll}1 & 1 & 1 & 0 & 0 & 0 & 0 & 0\end{array}$

*SECTION_SHELL_TITLE

Shell rigid

\$\# secid elform shrf nip propt qr/irid icomp setyp

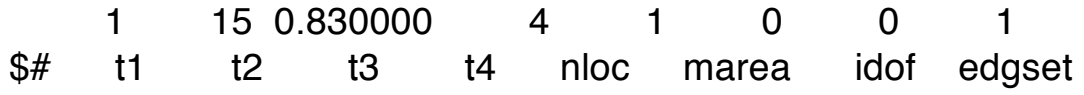

$\begin{array}{llllllll}0.100000 & 0.100000 & 0.100000 & 0.100000 & 0.000 & 0.000 & 0.000 & 0\end{array}$

*MAT_RIGID_TITLE

Die

\$\# mid ro $\mathrm{e}$ pr $\mathrm{n}$ couple $\mathrm{m}$ alias

$\begin{array}{llllll}17.8500 \mathrm{E}-6 & 2.1000 \mathrm{E}+5 & 0.300000 & 0.000 & 0.000 & 0.000\end{array}$

$\$ \#$ cmo con 1 con2

$\begin{array}{lll}1.000000 & 7 & 7\end{array}$

\$\# Ico or a1 a2 $\quad$ a3 $\quad$ v1 $\quad$ v2 $\quad$ v3

$\begin{array}{llllll}0.000 & 0.000 & 0.000 & 0.000 & 0.000 & 0.000\end{array}$

${ }^{*} \mathrm{PART}$

\$\# title

Lsheet

\$\# pid secid mid eosid hgid grav adpopt tmid

$\begin{array}{llllllll}2 & 2 & 7 & 0 & 2 & 0 & 0 & 0\end{array}$

*SECTION_SHELL_TITLE

Shell non rigid

\$\# secid elform shrf nip propt qr/irid icomp setyp $\begin{array}{llllllll}2 & 15 & 0.830000 & 6 & 1 & 0 & 0 & 1\end{array}$

$\$ \#$ t1 t2 t3 t4 nloc marea idof edgset

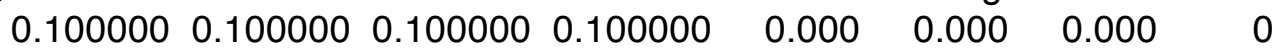

*MAT_BAMMAN_DAMAGE_TITLE

Mg damage bottom tension

\$\# mid ro $e$ pr $t$ hc

7 1.7700E-6 45000.000 $0.350000473 .00000 \quad 0.520000$

$\begin{array}{lllllllll}\$ \# & \mathrm{C} 1 & \mathrm{C} 2 & \mathrm{C} 3 & \mathrm{C} 4 & \mathrm{C} 5 & \mathrm{C} 6 & \mathrm{C} 7 & \mathrm{C} 8\end{array}$

15.4869002.0800E-25 3.471150 1278.8600 $0.0070481 .1100 \mathrm{E}-11 \quad 0.1132507 .1300 \mathrm{E}-34$ 
$\begin{array}{lllllllll}\$ \# & c 9 & c 10 & c 11 & c 12 & c 13 & c 14 & c 15 & c 16\end{array}$

$1.9100202085 .4099 \quad 0.0005 .7100 \mathrm{E}-132.1200 \mathrm{E}-335.2000 \mathrm{E}-192.40000054 .000000$

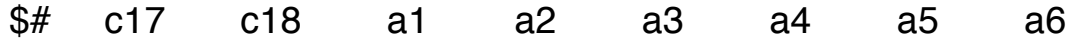

$\begin{array}{llllllll}0.000 & 0.000 & 0.000 & 0.000 & 0.000 & 0.000 & 0.000 & 0.000\end{array}$

$\$ \# \mathrm{n} \quad \mathrm{d} 0 \mathrm{fs}$

0.2680000 .0050008 .000000

*HOURGLASS_TITLE

Sheets

\$\# hgid inq qm ibq q1 q2 qb/vdc qw

$\begin{array}{llllllll}6 & 6 & 0.100000 & 1 & 1.500000 & 0.060000 & 0.100000 & 0.100000\end{array}$

*PART

\$\# title

Punch

\$\# pid secid mid eosid hgid grav adpopt tmid $\begin{array}{llllllll}3 & 1 & 2 & 0 & 0 & 0 & 0 & 0\end{array}$

*MAT_RIGID_TITLE

Pad and Punch

$\$ \#$ mid ro e pr $\mathrm{n}$ couple $\mathrm{m}$ alias

$\begin{array}{lllll}2 \text { 7.8500E-6 2.1000E +5 } & 0.300000 & 0.000 & 0.000 & 0.000\end{array}$

$\$ \#$ cmo con1 con2

$\begin{array}{lll}1.000000 & 6 & 7\end{array}$

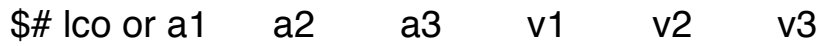

$\begin{array}{llllll}0.000 & 0.000 & 0.000 & 0.000 & 0.000 & 0.000\end{array}$

*PART

\$\# title

Pad

\$\# pid secid mid eosid hgid grav adpopt tmid

*PART

\$\# title

Rivet

\$\# pid secid mid eosid hgid grav adpopt tmid $\begin{array}{llllllll}5 & 2 & 4 & 0 & 1 & 0 & 0 & 0\end{array}$

*MAT_PIECEWISE_LINEAR_PLASTICITY_TITLE

Steel

$\$ \#$ mid ro e pr sigy etan fail tdel

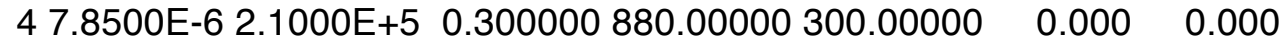

$\$ \# \quad c \quad p \quad$ Icss lcsr $\quad v p$

$\begin{array}{lllll}0.000 & 0.000 & 0 & 0 & 0.000\end{array}$

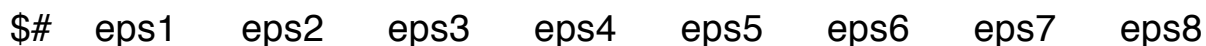

$\begin{array}{llllllll}0.000 & 0.000 & 0.000 & 0.000 & 0.000 & 0.000 & 0.000 & 0.000\end{array}$

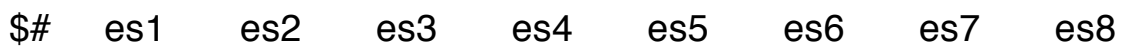

$\begin{array}{llllllll}0.000 & 0.000 & 0.000 & 0.000 & 0.000 & 0.000 & 0.000 & 0.000\end{array}$

*HOURGLASS_TITLE

rivet

\$\# hgid inq qm ibq q1 q2 qb/vdc qw

${ }^{*} \mathrm{PART}$

$\begin{array}{lllllll}6 & 0.150000 & 1 & 1.500000 & 0.060000 & 0.150000 & 0.150000\end{array}$

\$\# title 
Usheet

\$\# pid secid mid eosid hgid grav adpopt tmid $\begin{array}{llllllll}6 & 2 & 6 & 0 & 2 & 0 & 0 & 0\end{array}$

*MAT_BAMMAN_DAMAGE_TITLE

Mg damage top sheet

\$\# mid ro e pr t hc

6 1.7700E-6 45000.000 $0.350000473 .00000 \quad 0.520000$

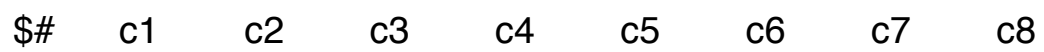

15.4869002.0800E-25 $3.4711501278 .8600 \quad 0.0070481 .1100 \mathrm{E}-11 \quad 0.1132507 .1300 \mathrm{E}-34$

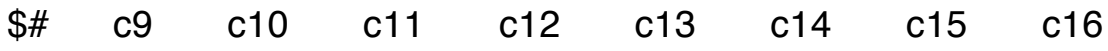

$1.9100202085 .4099 \quad 0.0005 .7100 \mathrm{E}-132.1200 \mathrm{E}-335.2000 \mathrm{E}-192.40000054 .000000$

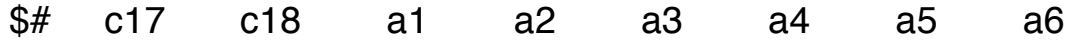

$\begin{array}{llllllll}0.000 & 0.000 & 0.000 & 0.000 & 0.000 & 0.000 & 0.000 & 0.000\end{array}$

$\$ \# \quad \mathrm{n} \quad \mathrm{d} 0 \mathrm{fs}$

$0.268000 \quad 0.0050004 .000000$

*PART

\$\# title

Bottom compression

\$\# pid secid mid eosid hgid grav adpopt tmid

$$
\begin{array}{llllllll}
7 & 2 & 8 & 0 & 2 & 0 & 0 & 0
\end{array}
$$

*MAT_BAMMAN_DAMAGE_TITLE

Mg damage Compression

\$\# mid ro e pr t hc

8 1.7700E-6 45000.000 0.350000 473.00000 0.520000

$\begin{array}{lllllllll}\$ \# & \text { c1 } & \text { c2 } & \text { c3 } & \text { c4 } & \text { c5 } & \text { c6 } & \text { c7 } & \text { c8 }\end{array}$

15.4869002.0800E-25 $3.4711501278 .8600 \quad 0.0070481 .1100 \mathrm{E}-11 \quad 0.1132507 .1300 \mathrm{E}-34$

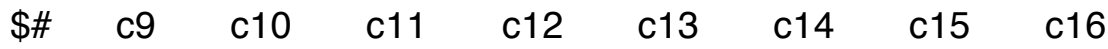

$1.9100202085 .4099 \quad 0.0005 .7100 E-132.1200 E-335.2000 E-192.40000054 .000000$

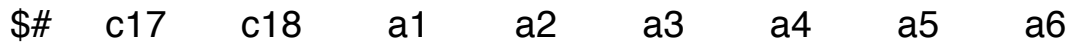

$\begin{array}{llllllll}0.000 & 0.000 & 0.000 & 0.000 & 0.000 & 0.000 & 0.000 & 0.000\end{array}$

$\$ \# \quad \mathrm{n} \quad \mathrm{d} 0$ fs

0.8000000 .00500015 .000000

*MAT_BAMMAN_TITLE

Bammann

$\$ \#$ mid ro e pr $\mathrm{t}$ hc

5 1.7700E-6 45000.000 $0.350000473 .00000 \quad 0.520000$

$\begin{array}{lllllllll}\$ \# & \text { c1 } & \text { c2 } & \text { c3 } & \text { c4 } & \text { c5 } & \text { c6 } & \text { c7 } & \text { c8 }\end{array}$

28.6770991.9500E-12 3.4211501278 .8600 2.634870 1.2910E-4 $0.0397138 .0400 \mathrm{E}-31$

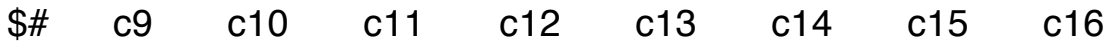

3.582272 1744.89561.0400E-198.8600E-114.0700E-115.2700E-164.5530E-17 0.002054

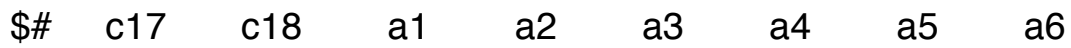

$\begin{array}{llllllll}0.000 & 0.000 & 0.000 & 0.000 & 0.000 & 0.000 & 0.000 & 0.000\end{array}$

*DEFINE_CURVE_TITLE

Displacement punch

$\begin{array}{cccccccc}\$ \# & \text { Icid } & \text { sidr } & \text { sfa } & \text { sfo } & \text { offa } & \text { offo } & \text { dattyp } \\ & 1 & 0 & 1.000000 & 1.000000 & 0.000 & 0.000 & 0\end{array}$

\$\# $\quad$ a1 $\quad 01$
0.000
0.000
0.0500000
0.2500000 


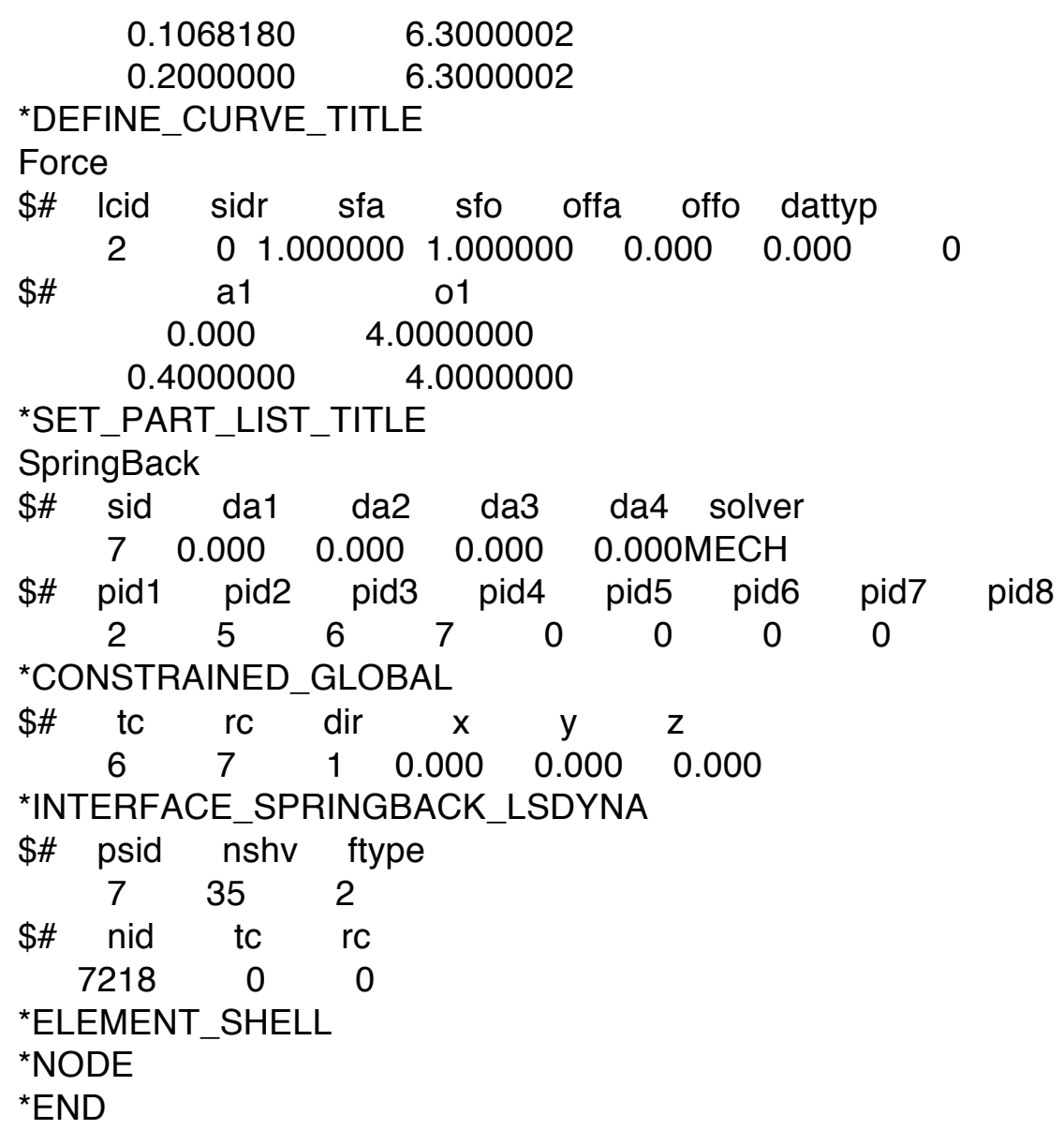


APPENDIX C. SAMPLE KEYWORD USED FOR SPRINGBACK PROCESS IN LS-DYNA

*KEYWORD

${ }^{*}$ TITLE

$\$ \#$ title

LS-DYNA keyword deck by LS-PrePost

${ }^{*}$ CONTROL_BULK_VISCOSITY

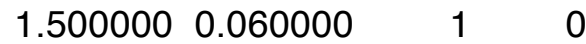

${ }^{*}$ CONTROL_CONTACT

$\begin{array}{cccccccc}0.300000 & 0.000 & 1 & 2 & 4 & 1 & 1 & 0 \\ 0 & 0 & 0 & 0 & 4.000000 & 0 & 0 & 0\end{array}$

$\begin{array}{lllllll}0.000 & 0.000 & 0.000 & 0.000 & 0.000 & 0.000 & 0.000\end{array}$

$\begin{array}{lllllll}0 & 0 & 0 & 0 & 0 & 0 & 0.000\end{array}$

$\begin{array}{llllllll}0 & 0 & 0 & 0.000 & 1.000000 & 0 & 0.000 & 0\end{array}$

0

*CONTROL_DYNAMIC_RELAXATION

\$\# nrcyck drtol drfctr drterm tssfdr irelal edttl idrflg

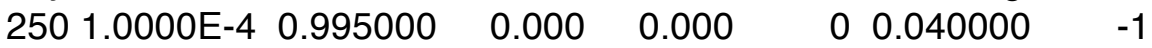

${ }^{*}$ CONTROL_ENERGY

${ }^{*}$ CONTROL_HOURGLASS

60.150000

${ }^{*}$ CONTROL_SHELL

$\begin{array}{cccccccc}20.000000 & 0 & -1 & 1 & 15 & 2 & 2 & 0 \\ 1.000000 & 0 & 0 & 1 & 0 & 0 & 0 & 0\end{array}$

${ }^{*}$ CONTROL_TERMINATION

\$\# endtim endcyc $\mathrm{dtmin}$ endeng endmas

$\begin{array}{lllll}0.000 & 0 & 0.000 & 0.000 & 0.000\end{array}$

${ }^{*}$ CONTROL_TIMESTEP

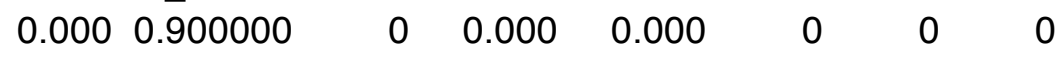

$0.000 \quad 0 \quad 0$

*DATABASE_BINARY_D3DRLF

\$\# dt lcdt beam npltc psetid

$\begin{array}{lllll}1.000000 & 0 & 0 & 0 & 0\end{array}$

*DATABASE_BINARY_D3PLOT

$\begin{array}{lllll}5.0000 \mathrm{E}-4 & 0 & 0 & 0 & 0\end{array}$

*DATABASE_EXTENT_BINARY

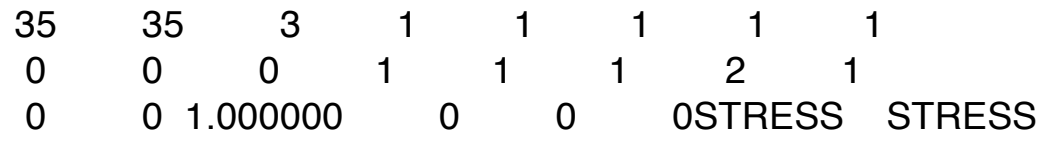


*BOUNDARY_PRESCRIBED_MOTION_RIGID_ID 1Punch

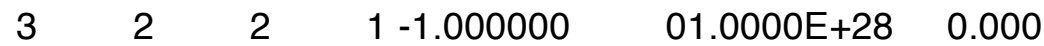

*BOUNDARY_PRESCRIBED_MOTION_RIGID_ID $2 \mathrm{Pad}$

$\begin{array}{lllllll}4 & 2 & 2 & 1-1.000000 & 0 & 0.050000 & 0.000\end{array}$

*LOAD_RIGID_BODY

$\begin{array}{lllllll}4 & 2 & 2-150.00000 & 0 & 0 & 0 & 0\end{array}$

*CONTACT_2D_AUTOMATIC_SURFACE_TO_SURFACE_ID

1Die Lsheet

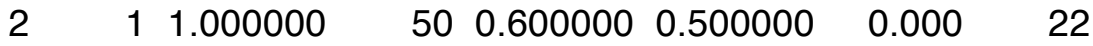

$\begin{array}{lllllll}0.0001 .0000 E+20 & 1.000000 & 1.000000 & 0 & 0 & 0 & 0\end{array}$

*SET_PART_LIST_TITLE

Lsheet

$\begin{array}{lllll}2 & 0.000 & 0.000 & 0.000 & 0.000 \mathrm{MECH}\end{array}$

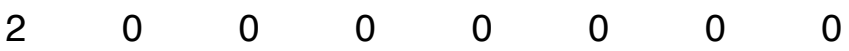

*SET_PART_LIST_TITLE

Die

$\begin{array}{lllll}1 & 0.000 & 0.000 & 0.000 & 0.000 \mathrm{MECH}\end{array}$

$\begin{array}{llllllll}1 & 0 & 0 & 0 & 0 & 0 & 0 & 0\end{array}$

${ }^{*}$ CONTACT_2D_AUTOMATIC_SURFACE_TO_SURFACE_ID

2Usheet Lsheet

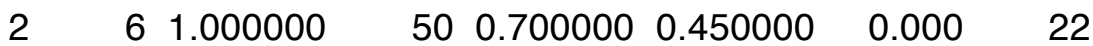

$\begin{array}{lllllll}0.0001 .0000 E+20 & 1.000000 & 1.000000 & 0 & 0 & 0 & 0\end{array}$

*SET_PART_LIST_TITLE

Usheet

$\begin{array}{llllll}6 & 0.000 & 0.000 & 0.000 & 0.000 \mathrm{MECH}\end{array}$

$\begin{array}{llllllll}6 & 0 & 0 & 0 & 0 & 0 & 0 & 0\end{array}$

*CONTACT_2D_AUTOMATIC_SURFACE_TO_SURFACE_ID

3Pad Usheet

$\begin{array}{llllllll}6 & 4 & 1.000000 & 50 & 0.600000 & 0.500000 & 0.000 & 22\end{array}$

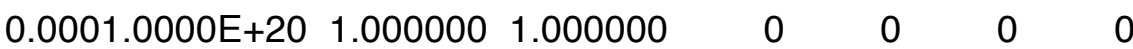

*SET_PART_LIST_TITLE

Pad

$\begin{array}{lllll}4 & 0.000 & 0.000 & 0.000 & 0.000 \mathrm{MECH}\end{array}$

$\begin{array}{llllllll}4 & 0 & 0 & 0 & 0 & 0 & 0 & 0\end{array}$

*CONTACT_2D_AUTOMATIC_SURFACE_TO_SURFACE_ID

4Rivet Usheet

$\begin{array}{llllllll}6 & 5 & 1.000000 & 50 & 0.150000 & 0.120000 & 0.000 & 22\end{array}$

$\begin{array}{lllllll}0.0001 .0000 E+20 & 1.000000 & 1.000000 & 0 & 0 & 0 & 0\end{array}$

*SET_PART_LIST_TITLE

Rivet

$\begin{array}{lllll}5 & 0.000 & 0.000 & 0.000 & 0.000 \mathrm{MECH}\end{array}$

$\begin{array}{llllllll}5 & 0 & 0 & 0 & 0 & 0 & 0 & 0\end{array}$

*CONTACT_2D_AUTOMATIC_SURFACE_TO_SURFACE_ID

5Rivet Lsheet

$\begin{array}{llllllll}2 & 5 & 1.000000 & 50 & 0.150000 & 0.120000 & 0.000 & 22\end{array}$

$\begin{array}{lllllll}0.0001 .0000 E+20 & 1.000000 & 1.000000 & 0 & 0 & 0 & 0\end{array}$

*CONTACT_2D_AUTOMATIC_SURFACE_TO_SURFACE_ID 


\section{Punch Rivet

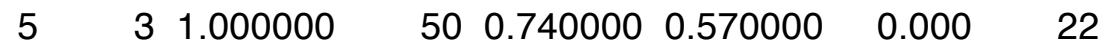 $\begin{array}{lllllll}0.0001 .0000 E+20 & 1.000000 & 1.000000 & 0 & 0 & 0 & 0\end{array}$ ${ }^{*}$ SET_PART_LIST_TITLE Punch \\ $\begin{array}{lllll}3 & 0.000 & 0.000 & 0.000 & 0.000 \mathrm{MECH}\end{array}$ \\ $\begin{array}{llllllll}3 & 0 & 0 & 0 & 0 & 0 & 0 & 0\end{array}$}

*CONTACT_2D_AUTOMATIC_SURFACE_TO_SURFACE_ID

7 Usheet Usheet

$\begin{array}{llllllll}6 & 6 & 1.000000 & 50 & 0.700000 & 0.450000 & 0.000 & 22\end{array}$

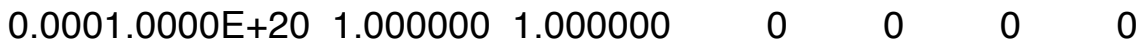

*CONTACT_2D_AUTOMATIC_SURFACE_TO_SURFACE_ID

8Lsheet Lsheet

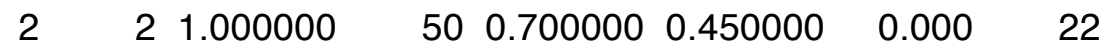

$\begin{array}{lllllll}0.0001 .0000 E+20 & 1.000000 & 1.000000 & 0 & 0 & 0 & 0\end{array}$

${ }^{*}$ CONTACT_2D_AUTOMATIC_SURFACE_TO_SURFACE_ID

9Lsheet compression Lsheet

$\begin{array}{llllllll}2 & 8 & 1.000000 & 50 & 0.700000 & 0.450000 & 0.000 & 22\end{array}$

$\begin{array}{lllllll}0.0001 .0000 \mathrm{E}+20 & 1.000000 & 1.000000 & 0 & 0 & 0 & 0\end{array}$

*SET_PART_LIST_TITLE

bottom Compression

$\begin{array}{lllll}8 & 0.000 & 0.000 & 0.000 & 0.000 \mathrm{MECH}\end{array}$

$\begin{array}{llllllll}7 & 0 & 0 & 0 & 0 & 0 & 0 & 0\end{array}$

*CONTACT_2D_AUTOMATIC_SURFACE_TO_SURFACE_ID

10Lsheet compression Usheet

$\begin{array}{llllllll}6 & 8 & 1.000000 & 50 & 0.700000 & 0.450000 & 0.000 & 22\end{array}$

$\begin{array}{lllllll}0.0001 .0000 E+20 & 1.000000 & 1.000000 & 0 & 0 & 0 & 0\end{array}$

${ }^{*}$ CONTACT_2D_AUTOMATIC_SURFACE_TO_SURFACE_ID

11Lsheet compression Lsheet comression

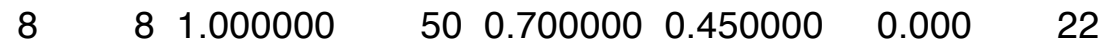

$\begin{array}{lllllll}0.0001 .0000 E+20 & 1.000000 & 1.000000 & 0 & 0 & 0 & 0\end{array}$

*CONTACT_2D_AUTOMATIC_SURFACE_TO_SURFACE_ID

12Die Lsheet compression

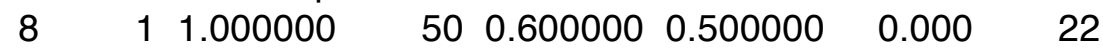

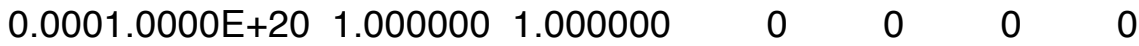

*CONTACT_2D_AUTOMATIC_SURFACE_TO_SURFACE_ID 13Rivet Lsheet compression

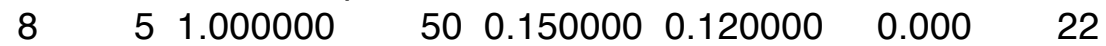

$\begin{array}{lllllll}0.0001 .0000 E+20 & 1.000000 & 1.000000 & 0 & 0 & 0 & 0\end{array}$

*PART

Die

$\begin{array}{llllllll}1 & 1 & 1 & 0 & 0 & 0 & 0 & 0\end{array}$

*SECTION_SHELL_TITLE

Shell rigid

$\begin{array}{ccccccccc}1 & 15 & 0.830000 & 4 & 1 & 0 & 0 & 1 & \\ 0.100000 & 0.100000 & 0.100000 & 0.100000 & 0.000 & 0.000 & 0.000 & 0\end{array}$

*MAT_RIGID_TITLE

Die

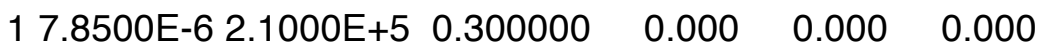




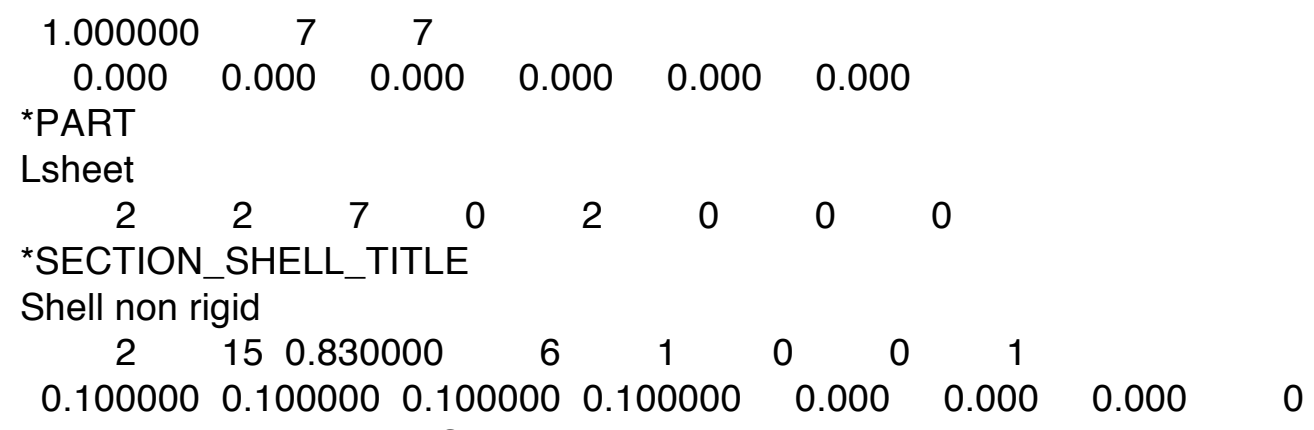


$1.9100202085 .4099 \quad 0.0005 .7100 \mathrm{E}-132.1200 \mathrm{E}-335.2000 \mathrm{E}-192.40000054 .000000$ $\begin{array}{llllllll}0.000 & 0.000 & 0.000 & 0.000 & 0.000 & 0.000 & 0.000 & 0.000\end{array}$

$0.268000 \quad 0.0050004 .000000$

*PART

Bottom compression

$\begin{array}{llllllll}7 & 2 & 8 & 0 & 2 & 0 & 0 & 0\end{array}$

*MAT_BAMMAN_DAMAGE_TITLE

Mg damage Compression

8 1.7700E-6 45000.000 $0.350000473 .00000 \quad 0.520000$

$15.4869002 .0800 \mathrm{E}-25 \quad 3.4711501278 .8600 \quad 0.0070481 .1100 \mathrm{E}-11 \quad 0.1132507 .1300 \mathrm{E}-34$

$1.9100202085 .4099 \quad 0.0005 .7100 \mathrm{E}-132.1200 \mathrm{E}-335.2000 \mathrm{E}-192.40000054 .000000$

$\begin{array}{llllllll}0.000 & 0.000 & 0.000 & 0.000 & 0.000 & 0.000 & 0.000 & 0.000\end{array}$

$0.800000 \quad 0.00500015 .000000$

*MAT_BAMMAN_TITLE

Bammann

5 1.7700E-6 45000.000 0.350000 473.00000 0.520000

28.6770991.9500E-12 $3.4211501278 .8600 \quad 2.634870$ 1.2910E-4 $0.0397138 .0400 E-31$

3.582272 1744.89561.0400E-198.8600E-114.0700E-115.2700E-164.5530E-17 0.002054

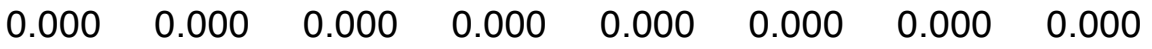

*DEFINE_CURVE_TITLE

Displacement punch

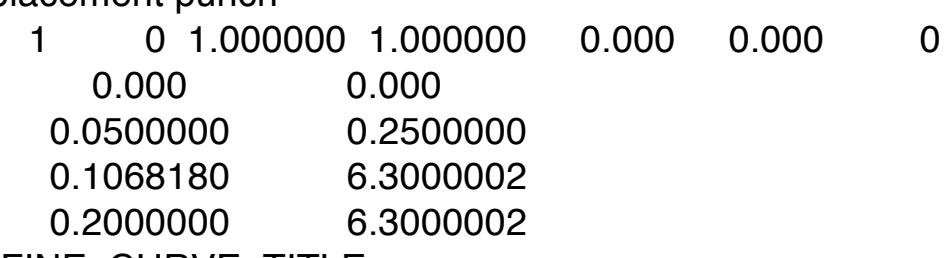

*DEFINE_CURVE_TITLE

Force

\begin{tabular}{|c|c|c|}
\hline \multirow{2}{*}{\multicolumn{2}{|c|}{ 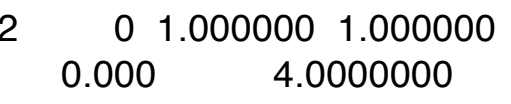 }} & \multirow[t]{3}{*}{0.000} \\
\hline & & \\
\hline 0.400000 & 4.0000000 & \\
\hline
\end{tabular}

*DEFINE_CURVE_TITLE

DR

\$\# Icid sidr sfa sfo offa offo dattyp

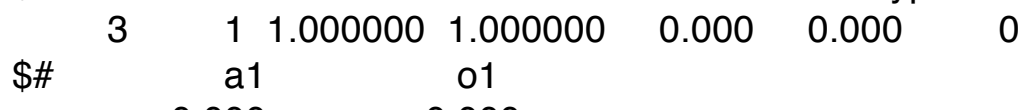

$0.000 \quad 0.000$

$1.0000000 \quad 1.0000000$

*SET_PART_LIST_TITLE

SpringBack

$\begin{array}{lllll}7 & 0.000 & 0.000 & 0.000 & 0.000 \mathrm{MECH}\end{array}$

${ }^{*}$ CONSTRAINED_GLOBAL

$\begin{array}{llllll}6 & 7 & 1 & 0.000 & 0.000 & 0.000\end{array}$

*INTERFACE_SPRINGBACK_LSDYNA

$\begin{array}{lll}7 & 35 & 2\end{array}$

$\begin{array}{lll}7218 & 0 & 0\end{array}$

${ }^{*} \mathrm{NODE}$

*ELEMENT_SHELL_THICKNESS 
*INITIAL_STRESS_SHELL

*INITIAL_STRAIN_SHELL

${ }^{\star}$ END 
APPENDIX D. SAMPLE KEYWORD USED FOR COOLING PROCESS IN LS-DYNA

${ }^{*}$ KEYWORD

*TITLE

\$\# title

LS-DYNA keyword deck by LS-PrePost

${ }^{*}$ CONTROL_BULK_VISCOSITY

\$\# q1 q2 type btype

$\begin{array}{llll}1.500000 & 0.060000 & 1 & 0\end{array}$

${ }^{*}$ CONTROL_CONTACT

\$\# slsfac rwpnal islchk shlthk penopt thkchg orien enmass

$\begin{array}{llllllll}0.300000 & 0.000 & 1 & 2 & 4 & 1 & 1 & 0\end{array}$

\$\# usrstr usrfrc nsbcs interm xpene ssthk ecdt tiedprj

$\begin{array}{llllllll}0 & 0 & 0 & 0 & 4.000000 & 0 & 0 & 0\end{array}$

$\$ \#$ sfric dfric edc vfc th th_sf pen_sf

$\begin{array}{lllllll}0.000 & 0.000 & 0.000 & 0.000 & 0.000 & 0.000 & 0.000\end{array}$

$\$ \#$ ignore frceng skiprwg outseg spotstp spotdel spothin

$\begin{array}{lllllll}0 & 0 & 0 & 0 & 0 & 0 & 0.000\end{array}$

\$\# isym nserod rwgaps rwgdth rwksf icov swradf ithoff

\$\# shledg

$\begin{array}{llllllll}0 & 0 & 0 & 0.000 & 1.000000 & 0 & 0.000 & 0\end{array}$

0

${ }^{*}$ CONTROL_DYNAMIC_RELAXATION

\$\# nrcyck drtol drfctr drterm tssfdr irelal edttl idrflg

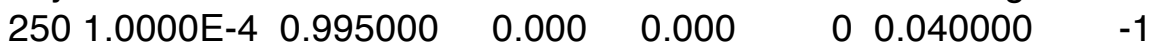

${ }^{*}$ CONTROL_ENERGY

\$\# hgen rwen slnten rylen

$\begin{array}{llll}1 & 2 & 1 & 1\end{array}$

${ }^{*}$ CONTROL_HOURGLASS

$\$ \#$ inq qh

60.150000

${ }^{*}$ CONTROL_SHELL

\$\# wrpang esort irnxx istupd theory bwc miter proj

$\begin{array}{lrcccccc}20.000000 & 0 & -1 & 1 & 15 & 2 & 2 & 0 \\ \$ \# \text { rotascl } & \text { intgrd } & \text { lamsht } & \text { cstyp6 } & \text { tshell } & \text { nfail1 } & \text { nfail4 } & \text { psnfail }\end{array}$

$\begin{array}{llllllll}1.000000 & 0 & 0 & 1 & 0 & 0 & 0 & 0\end{array}$

\$\# psstupd irquad cntco itsflg irquad

$\begin{array}{lllll}0 & 0 & 0 & 0 & 2\end{array}$

${ }^{*}$ CONTROL_TERMINATION

\$\# endtim endcyc dtmin endeng endmas

$\begin{array}{lllll}0.000 & 0 & 0.000 & 0.000 & 0.000\end{array}$

*CONTROL_TIMESTEP 
$\$ \#$ dtinit tssfac isdo tslimt dt2ms lctm erode ms1st

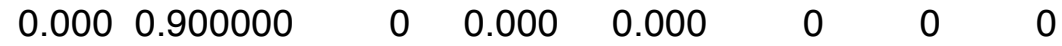

\$\# dt2msf dt2mslc imscl

$0.000 \quad 0 \quad 0$

*DATABASE_BINARY_D3DRLF

\$\# dt lcdt beam npltc psetid

$\begin{array}{lllll}1.000000 & 0 & 0 & 0 & 0\end{array}$

*DATABASE_BINARY_D3PLOT

$\$ \#$ dt lcdt beam npltc psetid

5.0000E-4 00000

$\$ \#$ ioopt

$$
0
$$

*DATABASE_EXTENT_BINARY

\$\# neiph neips maxint strflg sigflg epsflg rltflg engflg

$\begin{array}{llllllll}35 & 35 & 3 & 1 & 1 & 1 & 1 & 1\end{array}$

\$\# cmpflg ieverp beamip dcomp shge stssz n3thdt ialemat

$\begin{array}{llllllll}0 & 0 & 0 & 1 & 1 & 1 & 2 & 1\end{array}$

\$\# nintsld pkp_sen sclp unused msscl therm intout nodout

$$
\begin{array}{llllll}
0 & 0 & 1.000000 & 0 & 0 & \text { OSTRESS STRESS }
\end{array}
$$

*BOUNDARY_PRESCRIBED_MOTION_RIGID_ID

$\$ \#$ id

$$
\text { 1Punch }
$$

\$\# pid dof vad Icid sf vid death birth

$$
\begin{array}{llllll}
3 & 2 & 2 & 1-1.000000 & 01.0000 \mathrm{E}+28 & 0.000
\end{array}
$$

*BOUNDARY_PRESCRIBED_MOTION_RIGID_ID

$\$ \#$ id

heading

$$
2 \mathrm{Pad}
$$

\$\# pid dof vad lcid sf vid death birth

$\begin{array}{lllllll}4 & 2 & 2 & 1-1.000000 & 0 & 0.050000 & 0.000\end{array}$

*LOAD_RIGID_BODY

\$\# pid dof lcid sf $\quad$ cid $\quad \mathrm{m} 1 \quad \mathrm{~m} 2 \mathrm{m3}$

$\begin{array}{lllllll}4 & 2 & 2-150.00000 & 0 & 0 & 0 & 0\end{array}$

*CONTACT_2D_AUTOMATIC_SURFACE_TO_SURFACE_ID

$\$ \#$ cid

title

1Die Lsheet

$\$ \#$ sids sidm sfact freq fs fd $d c$ membs $\begin{array}{llllllll}2 & 1 & 1.000000 & 50 & 0.600000 & 0.500000 & 0.000 & 22\end{array}$

$\$ \#$ tbirth tdeath sos som nds ndm cof init

$\begin{array}{lllllll}0.0001 .0000 E+20 & 1.000000 & 1.000000 & 0 & 0 & 0 & 0\end{array}$

*SET_PART_LIST_TITLE

Lsheet

\$\# sid da1 da2 da3 da4 solver

$\begin{array}{lllll}2 & 0.000 & 0.000 & 0.000 & 0.000 \mathrm{MECH}\end{array}$

$\$ \#$ pid1 pid2 pid3 pid4 pid5 pid6 pid7 pid8

$\begin{array}{llllllll}2 & 0 & 0 & 0 & 0 & 0 & 0 & 0\end{array}$

*SET_PART_LIST_TITLE

Die

\$\# $\quad$ sid $\quad$ da1 da2 da3 da4 solver

$\begin{array}{lllll}1 & 0.000 & 0.000 & 0.000 & 0.000 \mathrm{MECH}\end{array}$ 


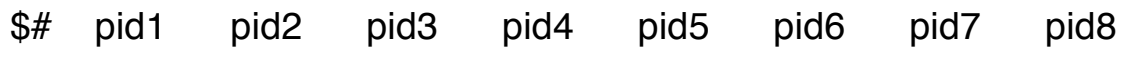
$\begin{array}{llllllll}1 & 0 & 0 & 0 & 0 & 0 & 0 & 0\end{array}$

*CONTACT_2D_AUTOMATIC_SURFACE_TO_SURFACE_ID

$\$ \#$ cid title 2Usheet Lsheet

\$\# sids sidm sfact freq fs $\mathrm{fd}$ dc membs

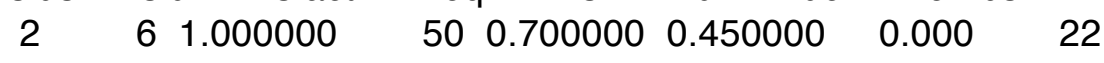

$\$ \#$ tbirth tdeath sos som nds ndm cof init $\begin{array}{lllllll}0.0001 .0000 E+20 & 1.000000 & 1.000000 & 0 & 0 & 0 & 0\end{array}$

*SET_PART_LIST_TITLE

Usheet

$\$ \#$ sid da1 da2 da3 da4 solver

$\begin{array}{lllll}6 & 0.000 & 0.000 & 0.000 & 0.000 \mathrm{MECH}\end{array}$

$\$ \#$ pid1 pid2 pid3 pid4 pid5 pid6 pid7 $\begin{array}{llllllll}6 & 0 & 0 & 0 & 0 & 0 & 0 & 0\end{array}$

${ }^{*}$ CONTACT_2D_AUTOMATIC_SURFACE_TO_SURFACE_ID

$\$ \#$ cid title 3Pad Usheet

\$\# sids sidm sfact freq fs fd dc membs $\begin{array}{llllllll}6 & 4 & 1.000000 & 50 & 0.600000 & 0.500000 & 0.000 & 22\end{array}$

$\$ \#$ tbirth tdeath sos som nds ndm cof init

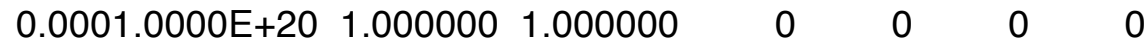

*SET_PART_LIST_TITLE

Pad

$\$ \#$ sid da1 da2 da3 da4 solver $\begin{array}{lllll}4 & 0.000 & 0.000 & 0.000 & 0.000 \mathrm{MECH}\end{array}$

$\$ \#$ pid1 pid2 pid3 pid4 pid5 pid6 $\begin{array}{llllllll}4 & 0 & 0 & 0 & 0 & 0 & 0 & 0\end{array}$

${ }^{*}$ CONTACT_2D_AUTOMATIC_SURFACE_TO_SURFACE_ID

$\$ \#$ cid title

4Rivet Usheet

\$\# sids sidm sfact freq fs fd dc membs

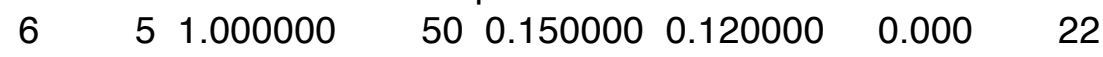

\$\# tbirth tdeath sos som nds ndm cof init $\begin{array}{lllllll}0.0001 .0000 E+20 & 1.000000 & 1.000000 & 0 & 0 & 0 & 0\end{array}$ *SET_PART_LIST_TITLE

Rivet

\$\# sid da1 da2 da3 da4 solver

$\begin{array}{lllll}5 & 0.000 & 0.000 & 0.000 & 0.000 \mathrm{MECH}\end{array}$

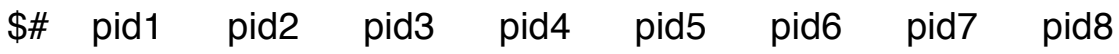
$\begin{array}{llllllll}5 & 0 & 0 & 0 & 0 & 0 & 0 & 0\end{array}$

${ }^{*}$ CONTACT_2D_AUTOMATIC_SURFACE_TO_SURFACE_ID $\$ \#$ cid title 5Rivet Lsheet

\$\# sids sidm sfact freq fs fd dc membs $\begin{array}{llllllll}2 & 5 & 1.000000 & 50 & 0.150000 & 0.120000 & 0.000 & 22\end{array}$

$\$ \#$ tbirth tdeath sos som nds ndm cof init $\begin{array}{llllll}0.0001 .0000 E+20 & 1.000000 & 1.000000 & 0 & 0 & 0\end{array}$ *CONTACT_2D_AUTOMATIC_SURFACE_TO_SURFACE_ID 


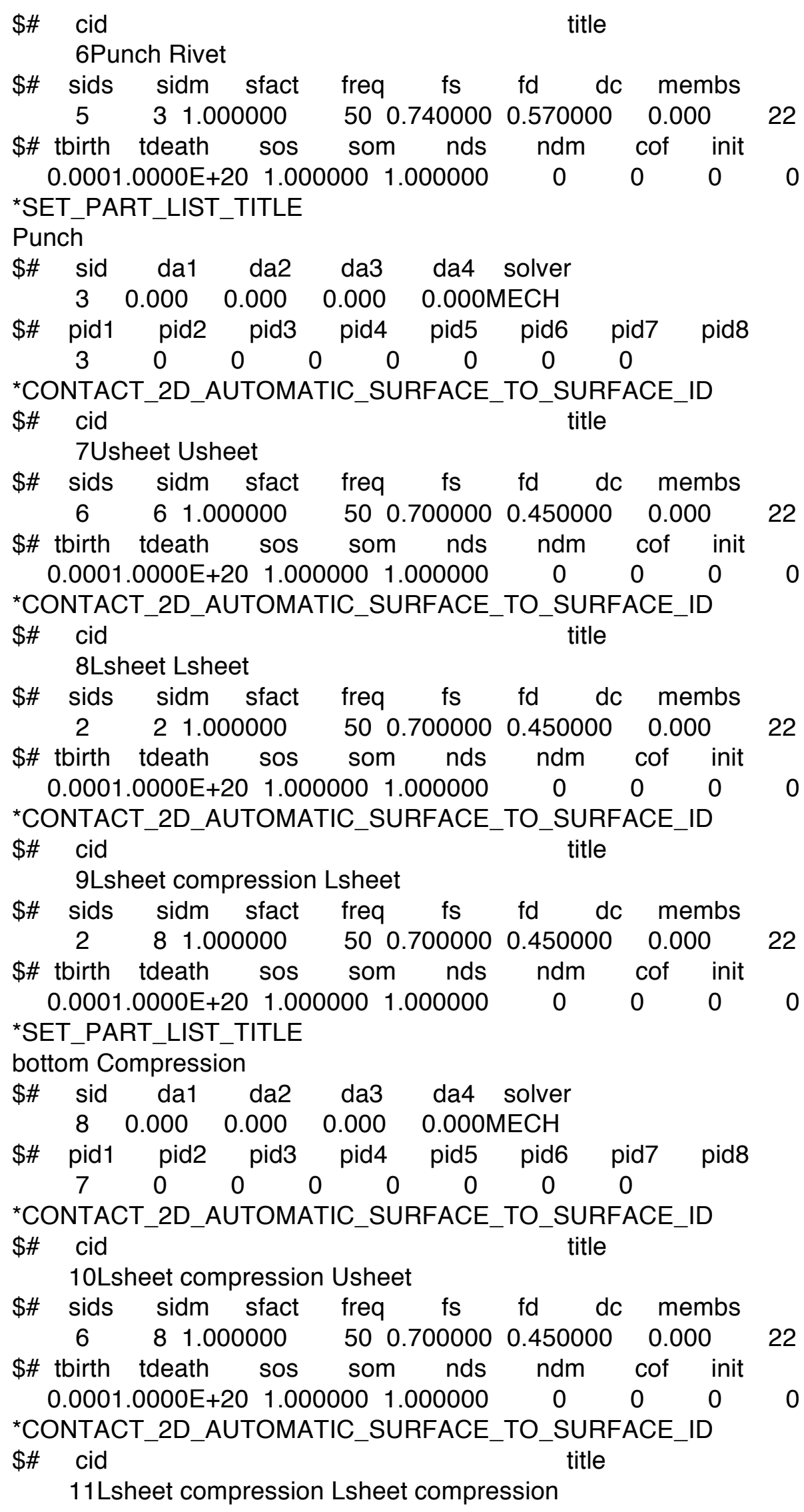


\$\# sids sidm sfact freq fs fd dc membs $\begin{array}{llllllll}8 & 8 & 1.000000 & 50 & 0.700000 & 0.450000 & 0.000 & 22\end{array}$

$\$ \#$ tbirth tdeath sos som nds ndm cof init $\begin{array}{lllllll}0.0001 .0000 E+20 & 1.000000 & 1.000000 & 0 & 0 & 0 & 0\end{array}$ *CONTACT_2D_AUTOMATIC_SURFACE_TO_SURFACE_ID

$\$ \#$ cid title 12Die Lsheet compression

\$\# sids sidm sfact freq fs fd dc membs $\begin{array}{llllllll}8 & 1 & 1.000000 & 50 & 0.600000 & 0.500000 & 0.000 & 22\end{array}$

$\$ \#$ tbirth tdeath sos som nds ndm cof init $\begin{array}{lllllll}0.0001 .0000 E+20 & 1.000000 & 1.000000 & 0 & 0 & 0 & 0\end{array}$ *CONTACT_2D_AUTOMATIC_SURFACE_TO_SURFACE_ID

$\$ \#$ cid title 13Rivet Lsheet compression

\$\# sids sidm sfact freq fs fd dc membs $\begin{array}{llllllll}8 & 5 & 1.000000 & 50 & 0.150000 & 0.120000 & 0.000 & 22\end{array}$

\$\# tbirth tdeath sos som nds ndm cof init $\begin{array}{lllllll}0.0001 .0000 E+20 & 1.000000 & 1.000000 & 0 & 0 & 0 & 0\end{array}$

*PART

\$\# title

Die

\$\# pid secid mid eosid hgid grav adpopt tmid $\begin{array}{llllllll}1 & 1 & 1 & 0 & 0 & 0 & 0 & 0\end{array}$

*SECTION_SHELL_TITLE

Shell rigid

\$\# secid elform shrf nip propt qr/irid icomp setyp

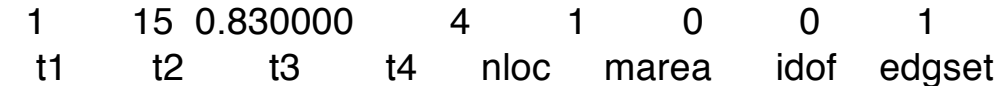

$\begin{array}{ccccccccc}\$ \# & \mathrm{t} 1 & \mathrm{t} 2 & \mathrm{t} 3 & \mathrm{t} 4 & \text { nloc } & \text { marea idof edgset } \\ & 0.100000 & 0.100000 & 0.100000 & 0.100000 & 0.000 & 0.000 & 0.000\end{array}$

*MAT_RIGID_TITLE

Die

$\$ \#$ mid ro $\mathrm{e}$ pr $\mathrm{n}$ couple $\mathrm{m}$ alias

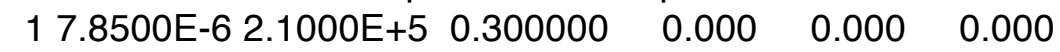

$\$ \# \quad$ cmo con 1 con2

$\begin{array}{lll}1.000000 & 7 & 7\end{array}$

\$\# Ico or a1 a2 a3 $\quad$ v1 $\quad$ v2 $\quad$ v3

$\begin{array}{llllll}0.000 & 0.000 & 0.000 & 0.000 & 0.000 & 0.000\end{array}$

*PART

\$\# title

Lsheet

\$\# pid secid mid eosid hgid grav adpopt tmid $\begin{array}{llllllll}2 & 2 & 7 & 0 & 2 & 0 & 0 & 0\end{array}$

*SECTION_SHELL_TITLE

Shell non rigid

\$\# secid elform shrf nip propt qr/irid icomp setyp

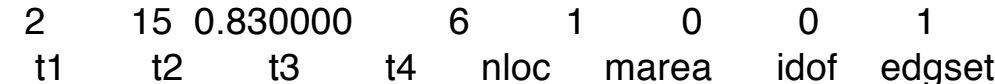

$\begin{array}{ccccccccc}\$ \# & \mathrm{t} 1 & \mathrm{t} 2 & \mathrm{t} 3 & \mathrm{t} 4 & \text { nloc } & \text { marea idof edgset } \\ 0.100000 & 0.100000 & 0.100000 & 0.100000 & 0.000 & 0.000 & 0.000\end{array}$ *MAT_BAMMAN_DAMAGE_TITLE 
Mg damage bottom tension

$\$ \#$ mid ro $\mathrm{e}$ pr $\mathrm{t}$ hc

7 1.7700E-6 45000.000 0.350000 473.00000 0.520000

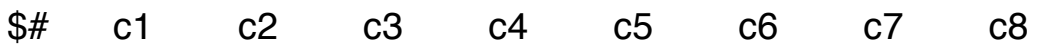

15.4869002.0800E-25 $3.4711501278 .8600 \quad 0.0070481 .1100 \mathrm{E}-11 \quad 0.1132507 .1300 \mathrm{E}-34$

$\begin{array}{lllllllll}\$ \# & c 9 & c 10 & c 11 & c 12 & c 13 & c 14 & c 15 & c 16\end{array}$

$1.9100202085 .4099 \quad 0.0005 .7100 E-132.1200 E-335.2000 E-192.40000054 .000000$

$\begin{array}{lllllllll}\$ \# & \mathrm{c} 17 & \mathrm{c} 18 & \text { a1 } & \text { a2 } & \text { a3 } & \text { a4 } & \text { a5 } & \text { a6 }\end{array}$

$\begin{array}{llllllll}0.000 & 0.000 & 0.000 & 0.000 & 0.000 & 0.000 & 0.000 & 0.000\end{array}$

$\$ \# \quad \mathrm{n} \quad \mathrm{d} 0$ fs

0.2680000 .0050008 .000000

*HOURGLASS_TITLE

Sheets

\$\# hgid inq qm ibq q1 q2 qb/vdc qw

$\begin{array}{llllllll}2 & 6 & 0.100000 & 1 & 1.500000 & 0.060000 & 0.100000 & 0.100000\end{array}$

*PART

\$\# title

Punch

\$\# pid secid mid eosid hgid grav adpopt tmid

*MAT_RIGID_TITLE

Pad and Punch

$\$ \#$ mid ro e pr $\mathrm{n}$ couple $\mathrm{m}$ alias

$\begin{array}{lllll}2 \text { 7.8500E-6 2.1000E+5 } & 0.300000 & 0.000 & 0.000 & 0.000\end{array}$

$\$ \# \quad$ cmo con 1 con2

$\begin{array}{lll}1.000000 & 6 & 7\end{array}$

\$\# Ico or a1 a2 a3 $\quad$ v1 $\quad$ v2 $\quad$ v3

$\begin{array}{llllll}0.000 & 0.000 & 0.000 & 0.000 & 0.000 & 0.000\end{array}$

*PART

\$\# title

Pad

\$\# pid secid mid eosid hgid grav adpopt tmid

*PART

\$\# title

Rivet

\$\# pid secid mid eosid hgid grav adpopt tmid

$\begin{array}{llllllll}5 & 2 & 4 & 0 & 1 & 0 & 0 & 0\end{array}$

*MAT_PIECEWISE_LINEAR_PLASTICITY_TITLE

Steel

\$\# mid ro e pr sigy etan fail tdel

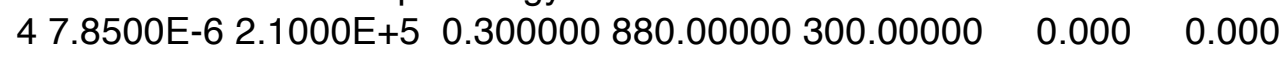

$\$ \# \quad c \quad p \quad$ lcss lcsr vp $\begin{array}{lllll}0.000 & 0.000 & 0 & 0 & 0.000\end{array}$

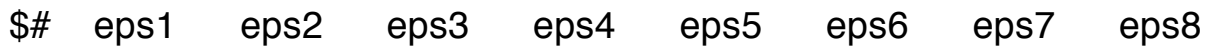

$\begin{array}{llllllll}0.000 & 0.000 & 0.000 & 0.000 & 0.000 & 0.000 & 0.000 & 0.000\end{array}$

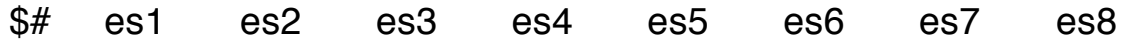

$\begin{array}{llllllll}0.000 & 0.000 & 0.000 & 0.000 & 0.000 & 0.000 & 0.000 & 0.000\end{array}$

${ }^{*}$ HOURGLASS_TITLE 
rivet

\$\# hgid inq qm ibq q1 q2 qb/vdc qw

$\begin{array}{llllllll}1 & 6 & 0.150000 & 1 & 1.500000 & 0.060000 & 0.150000 & 0.150000\end{array}$

*PART

\$\# title

Usheet

\$\# pid secid mid eosid hgid grav adpopt tmid $\begin{array}{llllllll}6 & 2 & 6 & 0 & 2 & 0 & 0 & 0\end{array}$

*MAT_BAMMAN_DAMAGE_TITLE

Mg damage top sheet

$\$ \#$ mid ro e pr t hc

6 1.7700E-6 45000.000 $0.350000473 .00000 \quad 0.520000$

$\begin{array}{lllllllll}\$ \# & \mathrm{c} 1 & \mathrm{c} 2 & \mathrm{c} 3 & \mathrm{c} 4 & \mathrm{c} 5 & \mathrm{c} 6 & \mathrm{c} 7 & \mathrm{c} 8\end{array}$

15.4869002.0800E-25 $3.4711501278 .8600 \quad 0.0070481 .1100 \mathrm{E}-11 \quad 0.1132507 .1300 \mathrm{E}-34$

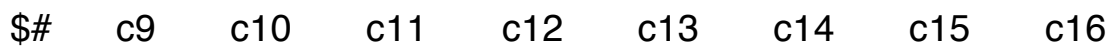

$1.9100202085 .4099 \quad 0.0005 .7100 E-132.1200 E-335.2000 E-192.40000054 .000000$

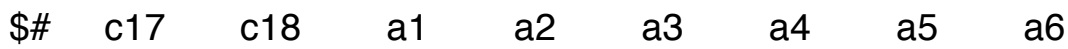

$\begin{array}{llllllll}0.000 & 0.000 & 0.000 & 0.000 & 0.000 & 0.000 & 0.000 & 0.000\end{array}$

$\$ \# \quad \mathrm{n} \quad \mathrm{d} 0 \quad \mathrm{fs}$

$0.268000 \quad 0.0050004 .000000$

*PART

\$\# title

Bottom compression

$\$ \#$ pid secid mid eosid hgid grav adpopt tmid $\begin{array}{llllllll}7 & 2 & 8 & 0 & 2 & 0 & 0 & 0\end{array}$

*MAT_BAMMAN_DAMAGE_TITLE

Mg damage Compression

$\$ \#$ mid ro e pr t hc

8 1.7700E-6 45000.000 $0.350000473 .00000 \quad 0.520000$

$\begin{array}{lllllllll}\$ \# & \mathrm{c} 1 & \mathrm{c} 2 & \mathrm{c} 3 & \mathrm{c} 4 & \mathrm{c} 5 & \mathrm{c} 6 & \mathrm{c} 7 & \mathrm{c} 8\end{array}$

15.4869002.0800E-25 $3.4711501278 .8600 \quad 0.0070481 .1100 \mathrm{E}-11 \quad 0.1132507 .1300 \mathrm{E}-34$

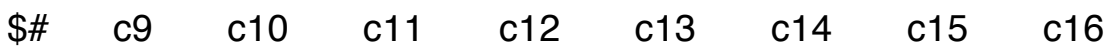

$1.9100202085 .4099 \quad 0.0005 .7100 E-132.1200 E-335.2000 E-192.40000054 .000000$

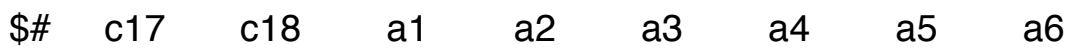

$\begin{array}{llllllll}0.000 & 0.000 & 0.000 & 0.000 & 0.000 & 0.000 & 0.000 & 0.000\end{array}$

$\$ \# \quad \mathrm{n} \quad \mathrm{d} 0 \quad \mathrm{fs}$

0.8000000 .00500015 .000000

*MAT_BAMMAN_TITLE

Bammann

\$\# mid ro e pr $\mathrm{t}$ hc

5 1.7700E-6 45000.000 $0.350000473 .00000 \quad 0.520000$

$\begin{array}{lllllllll}\$ \# & \text { c1 } & \text { c2 } & \text { c3 } & \text { c4 } & \text { c5 } & \text { c6 } & \text { c7 } & \text { c8 }\end{array}$

28.6770991.9500E-12 $3.4211501278 .8600 \quad 2.6348701 .2910 \mathrm{E}-4 \quad 0.0397138 .0400 \mathrm{E}-31$

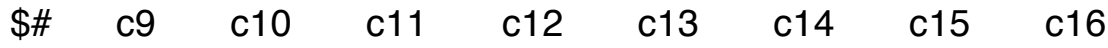

3.582272 1744.89561.0400E-198.8600E-114.0700E-115.2700E-164.5530E-17 0.002054

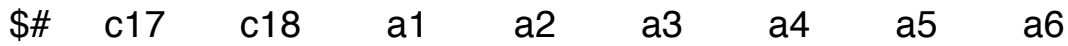

$\begin{array}{llllllll}0.000 & 0.000 & 0.000 & 0.000 & 0.000 & 0.000 & 0.000 & 0.000\end{array}$

*INITIAL_STRAIN_SHELL

*INITIAL_STRESS_SHELL 
*DEFINE_CURVE_TITLE

Displacement punch

\$\# Icid sidr sfa sfo offa offo dattyp

$\begin{array}{lllllll}1 & 0 & 1.000000 & 1.000000 & 0.000 & 0.000 & 0\end{array}$

\$\# $\quad$ a1 $\quad 01$

$0.000 \quad 0.000$

$0.0500000 \quad 0.2500000$

$0.1068180 \quad 6.3000002$

$0.2000000 \quad 6.3000002$

*DEFINE_CURVE_TITLE

Force

\$\# Icid sidr sfa sfo offa offo dattyp

$\begin{array}{lllllll}2 & 0 & 1.000000 & 1.000000 & 0.000 & 0.000 & 0\end{array}$

\$\# $\quad$ a1 $\quad 01$

$0.000 \quad 4.0000000$

$0.4000000 \quad 4.0000000$

*DEFINE_CURVE_TITLE

DR

\$\# Icid sidr sfa sfo offa offo dattyp

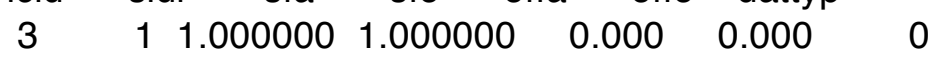

$\$ \# \quad \begin{array}{lll}\text { \$1 } & 01\end{array}$

$0.000 \quad 0.000$

$1.0000000 \quad 1.0000000$

*SET_PART_LIST_TITLE

SpringBack

$\$ \#$ sid da1 da2 da3 da4 solver $\begin{array}{lllll}7 & 0.000 & 0.000 & 0.000 & 0.000 \mathrm{MECH}\end{array}$

$\$ \#$ pid1 pid2 pid3 pid4 pid5 pid6 pid7 pid8

${ }^{*}$ CONSTRAINED_GLOBAL

$\$ \#$ tc $\quad$ rc $\quad$ dir $\quad x \quad y \quad z$

$\begin{array}{llllll}6 & 7 & 1 & 0.000 & 0.000 & 0.000\end{array}$

*INTERFACE_SPRINGBACK_LSDYNA

\$\# psid nshv ftype

$\begin{array}{lll}7 & 35 & 2\end{array}$

$\$ \#$ nid tc rc

$\begin{array}{lll}7218 & 0 & 0\end{array}$

`ELEMENT_SHELL_THICKNESS

*NODE

${ }^{\star}$ END 